\title{
UM ESTUDO DO COOPERATIVISMO DE CRÉDITO NO BRASIL
}

Benedito Geovani Martins de PAIVA ${ }^{1}$

Neusa Maria Bastos Fernandes dos SANTOS

\author{
${ }^{1}$ Doutorando em Administração pela Pontifícia Universidade Católica de São Paulo - PUC-SP. \\ benedito.geovani@yahoo.com.br
}

${ }^{2}$ Professora do Programa de Doutorado em Administração da Pontifícia Universidade Católica de São Paulo - PUC-SP. Email: admneusa@pucsp.br

Recebido em: 13/07/2016 - Aprovado em: 30/11/2017 - Disponibilizado em: 30/12/2017

\begin{abstract}
RESUMO
Apesar do crescimento nos últimos anos, a participação das cooperativas no Sistema Financeiro Nacional, no Brasil, ainda é muito pequena quando comparada com países como Áustria, França, Finlândia, Itália e Holanda. Atualmente, esta participação de mercado alcança patamares que variam de 25 a $50 \%$. A primeira cooperativa de crédito no Brasil foi constituída em 28 de dezembro de 1902, na cidade de Nova Petrópolis, no estado do Rio Grande do Sul, e ainda está em operação com a denominação de Cooperativa de Crédito de Livre Admissão de Associados Pioneira da Serra Gaúcha SICREDI Pioneira/RS. As cooperativas de crédito no Brasil foram, desde a origem, fortemente controladas e regulamentadas pela legislação. O presente artigo tem como objetivo apresentar a estrutura do Sistema Nacional de Crédito Cooperativo (SNCC) e sua participação no Sistema Financeiro Nacional (SFN) brasileiro. A metodologia utilizada foi a pesquisa bibliográfica e documental, com abordagem quantitativa. O estudo justifica-se pela importância do cooperativismo de crédito para o desenvolvimento das regiões menos favorecidas pelos bancos comerciais, como as pequenas cidades, possibilitando, assim, a inclusão financeira da baixa renda e ampliação do microcrédito. O SNCC é estruturado em um sistema de três níveis, sendo, o primeiro nível formado por 1.020 cooperativas de crédito singulares, o segundo nível por 35 cooperativas centrais e o terceiro nível por quatro Confederações e 2 bancos cooperativos. O SNCC representou apenas $2,71 \%$ do SFN, este último totalizou 3,17 trilhões de reais. Por fim, embora pequena, quando comparada a outros países, a participação das cooperativas de crédito no SFN tem registrado crescimento constante.
\end{abstract}

Palavras-chave: Banco Cooperativo. Cooperativa de Crédito. Microcrédito. Sistema Financeiro Nacional. Sistema Nacional de Crédito Cooperativo.

\begin{abstract}
Despite the growth in recent years, the participation of cooperatives in the National Financial System in Brazil is still very small when compared to countries such as Austria, France, Finland, Italy and the Netherlands. Nowadays this market share reaches levels ranging from 25 to $50 \%$. The first credit cooperative in Brazil was established on December 28, 1902, in the city of Nova Petrópolis, in the state of Rio Grande do Sul, still in operation under the name of Cooperativa de Livre Admissão de Associados Pioneira da Serra Gaúcha - SICREDI Pioneira / RS. Credit cooperatives in Brazil have been heavily controlled and regulated by legislation since the beginning. This article aims to present the structure of the National Cooperative Credit System (SNCC) and its participation in the Brazilian National Financial System (SFN). The methodology used was the bibliographical and documentary research, with quantitative approach. The study is justified by the importance of credit cooperativism for the development of less favored regions by commercial banks, such as small cities, thus enabling the financial inclusion of low income and expansion of microcredit. The SNCC is structured in a threetier system. The first level consists of 1,020 unique credit cooperatives, the second level by 35 central cooperatives and the third level by four Confederations and two cooperative banks. The SNCC represented only $2.71 \%$ of the SFN, the latter totaled RMB 3.17 trillion. At last although small compared to other countries, the participation of credit unions in the SFN has registered steady growth.
\end{abstract}

Keywords: Cooperative Bank. Credit cooperative. Microcredit. National Financial System. National Cooperative Credit System.

\section{INTRODUÇÃO}

As cooperativas de crédito, no Brasil, fazem parte do Sistema Financeiro Nacional (SFN), modelo que contribui para o desenvolvimento e crescimento sociocultural e econômico da região onde atua. Possibilita a movimentação financeira de seus cooperados com cheque especial e empréstimos a juros e taxas reduzidas, facilidade de acesso ao crédito 
e contribui para a formação da poupança e do microcrédito.

A atuação das cooperativas de crédito vem aumentando significativamente nos últimos anos, principalmente por praticarem as menores taxas sobre os empréstimos e custo das operações financeiras, além de oferecem as maiores taxas de remuneração sobre os depósitos aplicados na cooperativa, comparado ao sistema bancário e financeiro, comprovado nas cooperativas de crédito filiado ao Sistema de Cooperativas de Crédito do Brasil (SICOOB) (BRESSAN et al., 2013). Essa expansão das cooperativas de crédito contribui para o fortalecimento das pequenas empresas, responsáveis pela geração de emprego, mobilidade social, aumento da competitividade e eficiência econômica.

A primeira cooperativa de crédito no Brasil foi constituída em 28 de dezembro de 1902, na cidade de Nova Petrópolis, no estado do Rio Grande do Sul, denominada inicialmente de Caixa de Economia e Empréstimos Amstad, posteriormente de Caixa Rural de Nova Petrópolis, ainda em operação com a denominação de Cooperativa de Crédito de Livre Admissão de Associados Pioneira da Serra Gaúcha - SICREDI Pioneira/RS.

As cooperativas são mais do que uma simples instituição financeira, formadas pela união de forças e de pessoas que têm por objetivo social a mutualidade e a prestação de serviços financeiros a seus associados em suas atividades específicas, buscando apoiar e aprimorar a produção, a produtividade e a qualidade de vida, bem como a comercialização e industrialização dos bens produzidos, além de desenvolver programas de poupança, de uso racional do crédito e formação educacional dos cooperados no sentido de fomentar o cooperativismo. Fica evidente que a sobrevivência das cooperativas de crédito está atrelada à rentabilidade, com a prestação dos serviços, e à operação de captação e concessão de créditos aos cooperados.

Meinen e Port (2012) relatam que as cooperativas de crédito atuam,principalmente, em mercados nos quais os bancos têm menor atuação, como em pequenas cidades, sendo $46 \%$ dos associados de cooperativas financeiras oriundos de cidades com menos de 30 mil habitantes, localidades as quais provavelmente sentiram menos os efeitos da crise dos que os grandes centros urbanos. Assim, tem-se a questão problema: as cooperativas de crédito são expressivas no Sistema Financeiro Nacional?

$\mathrm{O}$ artigo tem como objetivo apresentar a estrutura do Sistema Nacional de Crédito Cooperativo (SNCC) e sua participação no SFN brasileiro.

Para isso, realizou-se pesquisa bibliográfica e documental, com abordagem quantitativa. $\mathrm{O}$ estudo justifica-se pela importância do cooperativismo de crédito para o desenvolvimento das regiões menos favorecidas pelos bancos comerciais, como as pequenas cidades, possibilitando assim a 
inclusão financeira da baixa renda e ampliação do microcrédito.

\section{COOPERATIVAS DE CRÉDITO}

No Brasil, a lei n. ${ }^{\circ}$ 5.764, de 13 de dezembro de 1971, define as cooperativas como sociedades de pessoas, com forma e natureza jurídica próprias, de natureza civil, não sujeitas à falência, constituídas para prestar serviços aos associados. São organizações sem fins lucrativos, constituídas a partir da reunião de um grupo de pessoas que, além de serem seus proprietários e, na grande maioria dos casos, seus administradores são também seus usuários, ou seja, fornecedores de recursos para suas atividades e/ou demandantes de serviços. A propriedade é definida pelo voto, na assembleia geral, e todos os cooperados possuem direitos iguais de participação nas decisões (SANTOS, 2016).

As cooperativas de crédito são instituições financeiras, constituídas sob a forma de sociedade cooperativa, que tem por objeto a prestação de serviços de intermediação financeira aos cooperados, como concessão de crédito e captação de depósitos à vista e a prazo. Conforme a legislação vigente, as cooperativas de crédito podem disponibilizar serviços de cobrança, de custódia, de recebimentos e pagamentos por conta de terceiros, sob convênio com instituições financeiras, instituições privadas e correspondentes (FONTES FILHO, COELHO e VENTURA, 2009). De acordo com Pinheiro (2008), as cooperativas de crédito são sociedades de pessoas unidas voluntariamente, com forma e natureza jurídica próprias, sem fins lucrativos, criadas com o objetivo de prestar serviços financeiros aos seus associados.

Pinheiro (2008, p. 7) define e destaca as atividades financeiras das cooperativas de crédito.

As cooperativas de crédito são instituições financeiras constituídas sob a forma de sociedade cooperativa, tendo por objeto a prestação de serviços financeiros aos associados, tais como concessão de crédito, captação de depósitos à vista e a prazo, cheques, prestação de serviços de cobrança, de custódia, de recebimentos e pagamentos por conta de terceiros sob convênio com instituições financeiras públicas e privadas e de correspondente no país, além de outras operações específicas e atribuições estabelecidas na legislação em vigor.

A cooperativa de crédito pode ser definida como uma instituição financeira constituída por uma sociedade de pessoas, com forma e natureza jurídica própria, sem fins lucrativos e não sujeita à falência. Tem como princípios fundamentais a união por adesão voluntária e livre, gestão democrática, participação econômica dos membros, autonomia e independência. Disponibilizam aos cooperados a maioria dos serviços dos bancos como conta corrente, aplicações financeiras, cartão de crédito, empréstimos e financiamentos, de modo mais simples e vantajoso. Os cooperados têm poder igual de voto, independentemente da sua cota de participação no capital social da cooperativa de crédito. 
O BACEN (2017 a) corrobora que as cooperativas prestam serviços financeiros de modo mais simples e vantajoso e também possibilita acesso ao crédito e a outros produtos financeiros como aplicações, investimentos, empréstimos, financiamentos, recebimento de contas e seguros. Os cooperados têm o controle e a direção, definidos pelo voto em assembleia. Os recursos captados pela poupança são direcionados aos cooperados, gerando desenvolvimento regional.

Assaf Neto (2011) define as cooperativas de crédito como instituições financeiras não bancárias, voltadas a viabilizar créditos aos seus cooperados, além de prestar serviços financeiros de acordo com sua classificação pelo Banco Central do Brasil (BACEN).

\subsection{Cooperativismos de crédito no Brasil}

A primeira cooperativa de crédito no Brasil foi constituída em 28 de dezembro de 1902, na cidade de Nova Petrópolis, no estado do Rio Grande do Sul, denominada inicialmente de Caixa de Economia e Empréstimos Amstad, posteriormente de Caixa Rural de Nova Petrópolis. Continua em operação com a denominação de Cooperativa de Crédito de Livre Admissão de Associados
Pioneira da Serra Gaúcha - SICREDI Pioneira/RS. No período entre 1902 e 1964, foram constituídas mais 66 cooperativas de crédito do tipo Raiffeisen no estado do Rio Grande do Sul. Em 1. ${ }^{\circ}$ de março de 1906, no município de Lajeado, no Estado do Rio Grande do Sul, foi constituída a primeira cooperativa de crédito do tipo Luzzatti no Brasil, com a denominação de Caixa Econômica de Empréstimo de Lajeado. Continua em operação com a denominação de Cooperativa de Crédito de Lajeado (PINHEIRO, 2008).

As cooperativas no Brasil integram o SFN, são reguladas pelo Conselho Monetário Nacional (CMN) e fiscalizadas pelo BACEN. O SFN é fortemente controlado pela legislação, o que garante a segurança da economia e de seus participantes. O controle e monitoramento feito pela legislação, desde a origem, contribuiu para a expansão das cooperativas de crédito, as quais atingem as regiões menos favorecidas pelos bancos comerciais como as pequenas cidades, possibilitando assim a inclusão financeira da baixa renda, ampliação do microcrédito e trazendo para essas regiões o desenvolvimento socioeconômico. O quadro 1 apresenta a evolução da legislação do cooperativismo de crédito no Brasil. 
Quadro 1 - Evolução das cooperativas de crédito no Brasil.

\begin{tabular}{|c|c|c|}
\hline Data & $\begin{array}{l}\text { Leis, Decretos e } \\
\text { Normas }\end{array}$ & Descrição \\
\hline $\begin{array}{l}06 \text { de janeiro de } \\
1903\end{array}$ & Decreto n. $^{\circ} 979$ & Permitiu aos sindicatos a organização de caixas rurais de crédito agrícola. \\
\hline $\begin{array}{l}05 \text { de janeiro de } \\
1907\end{array}$ & Decreto n..$^{\circ} 1637$ & $\begin{array}{l}\text { primeira norma a disciplinar o funcionamento das sociedades cooperativas e } \\
\text { onstituição }\end{array}$ \\
\hline $\begin{array}{l}20 \text { de junho de } \\
1907\end{array}$ & Decreto n. ${ }^{\circ} 6.532$ & $\begin{array}{l}\text { Estabeleceu que sindicatos agrícolas poderiam fundar uniões de sindicatos ou } \\
\text { sindicatos centrais, permitindo a livre admissão }\end{array}$ \\
\hline $\begin{array}{l}31 \text { de dezembro } \\
\text { de } 1925\end{array}$ & Lei n. $^{\circ} 4.984$ & $\begin{array}{l}\text { As cooperativas de crédito passaram a ser fiscalizadas pelo Ministério da } \\
\text { Agricultura, sem ônus, desobrigando de seguirem os sistemas Raiffeisen e Luzzatti, } \\
\text { da exigência de expedição de carta patente e de pagamento de quotas de } \\
\text { fiscalização. }\end{array}$ \\
\hline $\begin{array}{l}19 \text { de dezembro } \\
\text { de } 1932\end{array}$ & $\begin{array}{l}\text { Decreto }^{\circ} .^{\circ} \\
22.239\end{array}$ & $\begin{array}{l}\text { Estabeleceu que a autorização para criação de cooperativas dependeria de } \\
\text { aprovação governamental. }\end{array}$ \\
\hline $\begin{array}{l}10 \text { de julho de } \\
1934\end{array}$ & Decreto n. ${ }^{\circ} 2.647$ & $\begin{array}{l}\text { Distinguiu as cooperativas e classificou as cooperativas de crédito como de } \\
\text { cooperação profissional, permitiu sua formação por pessoas de profissões distintas. }\end{array}$ \\
\hline $\begin{array}{c}01 \text { de agosto de } \\
1938\end{array}$ & $\begin{array}{l}\text { Decreto-Lei } \\
\text { n. }^{\circ} 581\end{array}$ & $\begin{array}{l}\text { Transferiu para o Ministério da Fazenda a incumbência de fiscalizar as } \\
\text { cooperativas de crédito urbanas, mantendo as cooperativas de crédito rural sob } \\
\text { fiscalização do Ministério da Agricultura. Estabeleceu, ainda, que as caixas rurais } \\
\text { tipo Raiffeisen constituídas após a vigência do referido Decreto-Lei deveriam ter } \\
\text { área de operações restrita a uma pequena circunscrição rural, que poderia abranger } \\
\text { zonas municipais limítrofes. }\end{array}$ \\
\hline $\begin{array}{c}19 \text { de outubro de } \\
1943\end{array}$ & $\begin{array}{l}\text { Decreto-Lei } \\
\text { n. }{ }^{\text {o }} 5.893\end{array}$ & $\begin{array}{l}\text { Retornou ao Ministério da Agricultura a tarefa de fiscalizar todas as cooperativas, } \\
\text { independentemente do tipo, e criou a Caixa de Crédito Cooperativo, destinada ao } \\
\text { financiamento e fomento do cooperativismo. }\end{array}$ \\
\hline $\begin{array}{l}19 \text { de dezembro } \\
\text { de } 1945\end{array}$ & $\begin{array}{l}\text { Decreto-Lei } \\
\text { n. }^{\circ} 8.401\end{array}$ & $\begin{array}{l}\text { Devolveu a competência de fiscalizar as cooperativas em geral para o Serviço de } \\
\text { Economia Rural do Ministério da Agricultura }\end{array}$ \\
\hline $\begin{array}{l}10 \text { de abril de } \\
1950\end{array}$ & Lein. $^{\circ} 1.079$ & $\begin{array}{l}\text { Sobrestou, tendo em vista solicitação da Sumoc, sobre novos registros de } \\
\text { cooperativas de crédito no SER. }\end{array}$ \\
\hline $\begin{array}{c}13 \text { de agosto de } \\
1951\end{array}$ & Lei n. ${ }^{\circ} 1.412$ & $\begin{array}{l}\text { Modernizou a Caixa de créditos para Banco nacional de créditos Cooperativos, } \\
\text { com intuito de promover assistência e amparo às cooperativas, possibilitando } \\
\text { assim que a participação indireta das cooperativas de crédito que captassem } \\
\text { depósitos à vista na Câmara de Compensação de Cheques. }\end{array}$ \\
\hline $\begin{array}{c}15 \text { de abril de } \\
1958\end{array}$ & $\begin{array}{c}\text { Decreto } \\
\text { n. } .^{\circ} 43.552\end{array}$ & $\begin{array}{l}\text { Reforçou a competência da Sumoc para vistoriar e fiscalizar as cooperativas de } \\
\text { crédito, entre elas também as cooperativas mistas com seção de crédito, no que se } \\
\text { relaciona às normas gerais reguladoras da moeda e do crédito. }\end{array}$ \\
\hline $\begin{array}{l}12 \text { de novembro } \\
\text { de } 1962\end{array}$ & $\begin{array}{l}\text { Decreto } \\
\text { n. }^{\circ} 1.503\end{array}$ & $\begin{array}{l}\text { Liberou as autorizações e os registros de novas cooperativas de crédito ou com } \\
\text { seções de crédito. }\end{array}$ \\
\hline $\begin{array}{l}31 \text { de dezembro } \\
\text { de } 1964\end{array}$ & Lei n. ${ }^{\circ} 4.595$ & As cooperativas de crédito equipararam-se às demais instituições financeiras. \\
\hline $\begin{array}{l}20 \text { de dezembro } \\
\text { de } 1965\end{array}$ & $\begin{array}{c}\text { Resolução } \\
\text { BACEN n. }^{\circ} 11\end{array}$ & $\begin{array}{l}\text { Autorizou a constituição e o funcionamento de cooperativas de crédito, sob duas } \\
\text { modalidades: cooperativas de crédito de produção rural e cooperativas de crédito } \\
\text { com quadro social. }\end{array}$ \\
\hline $\begin{array}{c}28 \text { de janeiro de } \\
1966\end{array}$ & $\begin{array}{c}\text { Resolução } \\
\text { BACEN n. }^{\circ} 15\end{array}$ & $\begin{array}{l}\text { Decretou que somente poderia ser realizada pelas cooperativas de crédito a } \\
\text { captação de depósitos à vista de seus associados e não podiam deixar de distribuir } \\
\text { seus lucros com os associados. }\end{array}$ \\
\hline $\begin{array}{l}30 \text { de junho de } \\
1966\end{array}$ & $\begin{array}{c}\text { Resolução } \\
\text { BACEN n. }^{\circ} 27\end{array}$ & $\begin{array}{l}\text { Estabeleceu que as cooperativas de crédito e as seções de crédito somente } \\
\text { poderiam receber depósitos de pessoas físicas, funcionários ou instituições } \\
\text { relacionadas aos associados. }\end{array}$ \\
\hline $\begin{array}{l}21 \text { de novembro } \\
\text { de } 1966\end{array}$ & $\begin{array}{l}\text { Decreto-Lei n. } \\
\quad 59\end{array}$ & $\begin{array}{l}\text { Define a política nacional de cooperativismo, cria o Conselho Nacional do } \\
\text { Cooperativismo e dá outras Providências. }\end{array}$ \\
\hline $\begin{array}{l}19 \text { de abril de } \\
1967\end{array}$ & $\begin{array}{l}\text { Decreto n. }^{\circ} \\
60.597\end{array}$ & Regulamenta o Decreto-Lei n. ${ }^{\circ}$ 59, de 21 de novembro de 1966. \\
\hline $\begin{array}{l}19 \text { de setembro } \\
\text { de } 1968\end{array}$ & $\begin{array}{c}\text { Resolução } \\
\text { BACEN n. }{ }^{\circ} 99\end{array}$ & Liberou o funcionamento de cooperativas de crédito rural. \\
\hline $\begin{array}{l}25 \text { de março de } \\
1970\end{array}$ & $\begin{array}{l}\text { Decreto-Lei n. }^{\circ} \\
\quad 1.098\end{array}$ & $\begin{array}{l}\text { Delimitou que as cooperativas de crédito estavam sujeitas a algumas exigências } \\
\text { para que o Governo autorizasse a constituição. }\end{array}$ \\
\hline $\begin{array}{l}16 \text { de dezembro } \\
\text { de } 1971\end{array}$ & Lein. $^{\circ} 5.764$ & $\begin{array}{l}\text { Implantou o regime jurídico vigente das sociedades cooperativas. Definiu as } \\
\text { cooperativas como sociedades de pessoas de natureza civil. }\end{array}$ \\
\hline $\begin{array}{l}5 \text { de outubro de } \\
1988\end{array}$ & $\begin{array}{l}\text { Constituição } \\
\text { Federal } 1988\end{array}$ & $\begin{array}{l}\text { Determinou que as cooperativas de crédito continuam dependentes de prévia } \\
\text { aprovação do Banco Central do Brasil para funcionar (art.5). }\end{array}$ \\
\hline
\end{tabular}




\begin{tabular}{|c|c|c|}
\hline $\begin{array}{l}12 \text { de abril de } \\
1990\end{array}$ & Lei n. ${ }^{\circ} 8.029$ & Exclusão do Banco Nacional de Crédito Cooperativo S.A. - BNCC. \\
\hline $\begin{array}{l}11 \text { de março de } \\
1992\end{array}$ & $\begin{array}{c}\text { Resolução } \\
\text { BACEN n. }{ }^{\circ} 1.914\end{array}$ & $\begin{array}{l}\text { Vedou a constituição de cooperativas de crédito do tipo Luzzatti, e definiu as } \\
\text { autorizações para as cooperativas de economia e crédito mútuo e rural. }\end{array}$ \\
\hline $\begin{array}{l}19 \text { de janeiro de } \\
1994\end{array}$ & $\begin{array}{c}\text { Resolução } \\
\text { BACEN n. }{ }^{\circ} 2.099\end{array}$ & $\begin{array}{l}\text { Concedeu a permissão para criação das unidades de Postos de Atendimento } \\
\text { Cooperativo (PAC). }\end{array}$ \\
\hline $\begin{array}{l}31 \text { de agosto de } \\
1995\end{array}$ & $\begin{array}{c}\text { Resolução } \\
\text { BACEN n. }{ }^{\circ} 2.193\end{array}$ & $\begin{array}{l}\text { Permitiu a criação dos bancos cooperativos, ou seja, os bancos comerciais } \\
\text { controlados por cooperativas de crédito. }\end{array}$ \\
\hline $\begin{array}{l}27 \text { de maio de } \\
1999\end{array}$ & $\begin{array}{c}\text { Resolução } \\
\text { BACEN n. }{ }^{\circ} 2.608\end{array}$ & $\begin{array}{l}\text { Possibilitou às cooperativas centrais o poder de supervisionar o funcionamento das } \\
\text { outras cooperativas singulares e filiadas e também de realizar auditoria. }\end{array}$ \\
\hline $\begin{array}{l}30 \text { de agosto de } \\
2000\end{array}$ & $\begin{array}{c}\text { Resolução } \\
\text { BACEN n. }{ }^{\circ} 2.771\end{array}$ & $\begin{array}{l}\text { Reduziu os limites mínimos de patrimônio líquido, de acordo com o grau de risco } \\
\text { do ativo, passivo e contas de compensação. }\end{array}$ \\
\hline $\begin{array}{l}20 \text { de dezembro } \\
\text { de } 2002\end{array}$ & $\begin{array}{l}\text { Resolução } \\
\text { BACEN n. }{ }^{\circ} 3.058\end{array}$ & $\begin{array}{l}\text { Autorizou a formação de cooperativas compostas por pequenos empresários, } \\
\text { microempresários e microempreendedores, responsáveis por negócios de natureza } \\
\text { industrial, comercial ou de prestação de serviços, incluída a área rural. }\end{array}$ \\
\hline $\begin{array}{l}25 \text { de junho de } \\
2003\end{array}$ & $\begin{array}{c}\text { Resolução } \\
\text { BACEN n. }{ }^{\circ} 3.106\end{array}$ & $\begin{array}{l}\text { Permitiu que as cooperativas pudessem admitir associados em localidades com } \\
\text { menos de cem mil habitantes. }\end{array}$ \\
\hline $\begin{array}{l}27 \text { de novembro } \\
\text { de } 2003\end{array}$ & $\begin{array}{c}\text { Resolução } \\
\text { BACEN n. }{ }^{\circ} 3.140\end{array}$ & $\begin{array}{l}\text { rativas de crédito de empresários participantes de } \\
\text { ente a um mesmo sindicato patronal. }\end{array}$ \\
\hline $\begin{array}{l}17 \text { de dezembro } \\
\text { de } 2003\end{array}$ & $\begin{array}{c}\text { Resolução } \\
\text { BACEN no } 3.156\end{array}$ & $\begin{array}{l}\text { ondentes no País, } \\
\text { as. }\end{array}$ \\
\hline $\begin{array}{l}19 \text { de março de } \\
2004\end{array}$ & $\begin{array}{c}\text { Resolução } \\
\text { BACEN n. }{ }^{\circ} 3.188\end{array}$ & Autorizou aos bancos cooperativos o recebimento de depósitos de poupança rural. \\
\hline $\begin{array}{l}21 \text { de janeiro de } \\
2005\end{array}$ & $\begin{array}{l}\text { Resolução CFC } \\
\text { n. }{ }^{\text {o }} 1.013\end{array}$ & prova a NBC T 10.8 - IT - 01 - Entidades Cooperativas. \\
\hline $\begin{array}{l}31 \text { de agosto de } \\
2005\end{array}$ & $\begin{array}{l}\text { Resolução } \\
\text { BACEN n. }{ }^{\circ} 3.309\end{array}$ & m atividades relacionadas à distribuição e mediação $d$ \\
\hline $\begin{array}{l}30 \text { de setembro } \\
\text { de } 2005\end{array}$ & ção & condições \\
\hline $\begin{array}{l}9 \text { de agosto de } \\
2007\end{array}$ & $\begin{array}{l}\text { Resolução } \\
\text { BACEN n. }{ }^{\circ} 3.442\end{array}$ & $\begin{array}{l}\text { rificou a necessidade da governança corporativa e a criação da Entidade de } \\
\text { uditoria Coorporativa, possibilitando a transformação de cooperativas de crédito } \\
\text { livre admissão em áreas de ação com até dois milhões de habitantes. }\end{array}$ \\
\hline $\begin{array}{l}17 \text { de abril de } \\
2009\end{array}$ & $\begin{array}{l}\text { Lei } \\
\text { Complementar } n .^{\circ} \\
130\end{array}$ & $\begin{array}{l}\text { Regulamentou para todas as instituições financeiras constituídas sob a forma de } \\
\text { cooperativas de crédito com a CF/ } 88 \text {; grande passo para a Governança } \\
\text { Corporativa, possibilitou a criação de um Fundo Garantidor para o sistema. }\end{array}$ \\
\hline $\begin{array}{l}27 \text { de maio de } \\
2010\end{array}$ & $\begin{array}{c}\text { Resolução } \\
\text { BACEN n. }{ }^{\circ} 3.859\end{array}$ & $\begin{array}{l}\text { Libera a autorização para funcionamento, as alterações estatutárias e o } \\
\text { cancelamento de autorização para funcionamento de cooperativas de crédito. }\end{array}$ \\
\hline $\begin{array}{l}26 \text { de abril de } \\
\quad 2012\end{array}$ & $\begin{array}{l}\text { Resolução } \\
\text { BACEN n. }{ }^{\circ} 4.072\end{array}$ & $\begin{array}{l}\text { Modifica e ressalta sobre as normas de instalação, no País, de dependências de } \\
\text { instituições financeiras e demais instituições autorizadas a funcionar pelo Banco } \\
\text { Central do Brasil. }\end{array}$ \\
\hline $\begin{array}{l}28 \text { de junho de } \\
2013\end{array}$ & $\begin{array}{l}\text { Resolução } \\
\text { ACEN n. }{ }^{\circ} 4.243\end{array}$ & Dispõe sobre a constituição e o funcionamento de cooperativas de crédito. \\
\hline $\begin{array}{l}5 \text { de novembro de } \\
2013\end{array}$ & $\begin{array}{c}\text { Resolução } \\
\text { BACEN n. }{ }^{\circ} 4.284\end{array}$ & $\begin{array}{l}\text { tidor do Cooperativismo de } \\
\text { ão. }\end{array}$ \\
\hline $\begin{array}{l}5 \text { de agosto de } \\
2015\end{array}$ & $\begin{array}{l}\text { Resolução } \\
\text { BACEN n. }{ }^{\circ} 4.434\end{array}$ & $\begin{array}{l}\text { Relata sobre a constituição, a liberação para funcionamento, o funcionamento, as } \\
\text { alterações estatutárias e o cancelamento de autorização para funcionamento das } \\
\text { cooperativas de crédito e dá outras providências. }\end{array}$ \\
\hline $\begin{array}{l}17 \text { de dezembro } \\
\text { de } 2015\end{array}$ & $\begin{array}{r}\text { Reso } \\
\text { ACEN }\end{array}$ & Dispõe sobre auditoria cooperativa no segmento de cooperativas de crédito. \\
\hline $\begin{array}{l}24 \text { de novembro } \\
\text { de } 2016\end{array}$ & $\begin{array}{l}\text { Resolução } \\
\text { BACEN n. }{ }^{\circ} 4.538\end{array}$ & $\begin{array}{l}\text { Definiu que as instituições financeiras e demais instituições estão autorizadas a } \\
\text { funcionar pelo Banco Central do Brasil e que devem implementar e manter política } \\
\text { de sucessão de administradores, aplicável aos cargos da alta administração da } \\
\text { instituição. }\end{array}$ \\
\hline $\begin{array}{l}30 \text { de janeiro de } \\
2017\end{array}$ & $\begin{array}{l}\text { Resolução } \\
\text { BACEN n. }{ }^{\circ} 4.553\end{array}$ & $\begin{array}{l}\text { Estabeleceu a segmentação do conjunto das instituições financeiras e demais } \\
\text { instituições autorizadas a funcionar pelo BACEN para fins de aplicação } \\
\text { proporcional da regulação prudencial. }\end{array}$ \\
\hline
\end{tabular}

Fonte: Elaborado pelos autores (2017). 
As cooperativas de crédito foram criadas pelo Decreto 979, em 6 de janeiro de 1903, passaram a ser regulamentadas pela Lei n. ${ }^{\circ}$ 5.764, de 16 de dezembro de 1971. Consolidaram-se no mercado com a aprovação da legislação responsável pela segurança jurídica no Brasil, como a promulgação da Constituição da República, em 05 de outubro de 1988 e do Código Civil pela Lei n. ${ }^{\text {o } 10.406, \text { de }}$ 10 de janeiro de 2002. A Lei Complementar n. ${ }^{\circ}$ 130, de 17 de abril de 2009, criou o SNCC e, até hoje, é o principal marco regulatório do segmento cooperativista de crédito.

O SNCC está regulamentado de acordo com a Lei 4.595, de 31 de dezembro de 1964, a qual instituiu a Reforma Bancária e criou o CMN, Lei n. ${ }^{\circ}$ 5.764, de 16 de dezembro de 1971, a lei do cooperativismo, que definiu a Política Nacional de Cooperativismo, institui o regime jurídico das sociedades cooperativas, Lei complementar n. ${ }^{\circ} 130$, de 17 de abril de 2009, que deliberou sobre o SNCC e revoga dispositivos das Leis n. ${ }^{\circ}$ 4.595, de 31 de dezembro de 1964 , e da lei n. ${ }^{\circ} 5.764$, de 16 de dezembro de 1971 e pela Resolução n. ${ }^{\circ}$ 4.434, de 5 de agosto de 2015, que definiu a constituição, a autorização para funcionamento, o funcionamento, as alterações estatutárias e o cancelamento de autorização para funcionamento das cooperativas de crédito e outras providências.

A evolução da legislação de monitoramento e controle das cooperativas de crédito desempenhou importante papel na solidez do SNCC no País, ao mesmo tempo em que garantiu a sua expansão. Esses fatores permitem as cooperativas de crédito operarem com taxas de juro mais baixas, atendimento personalizado, concessão do crédito mais rápido, menor burocrática e presença nas regiões menos privilegiadas pelos bancos comerciais de varejo como nas cidades de menor porte, contribuindo assim para a proliferação do microcrédito e o desenvolvimento econômico do Brasil.

\subsection{Sistema Nacional de Crédito Cooperativo}

O SNCC está estruturado em um sistema de três níveis: o primeiro nível, as cooperativas singulares; o segundo, as cooperativas centrais ou federações de cooperativas e terceiro, as confederações de cooperativas e os bancos cooperativos. A maioria das cooperativas de crédito é organizada de forma sistêmica, compartilhando entre si sistemas e serviços para ganho de escala. Contudo, algumas cooperativas singulares na busca de modelos mais simplificados ou outras circunstâncias operacionais específicas como, por exemplo, apoio de outras instituições não cooperativas ou o uso de convênios de prestação de serviço, optam por atuar de forma independente, sem filiação a sistemas.

Assim, o SNCC está estruturado, no Brasil, de forma verticalizada para buscar ganho de escala e eficiência. No topo, encontrase banco cooperativo faz a conexão entre os sistemas bancário e as confederações de 
créditos, seguindo pelas cooperativas centrais e cooperativas singulares na base. A maior parte das cooperativas singulares e cooperativas centrais são filiadas ao SICOOB Confederação e utilizam os serviços do Banco Cooperativo do Brasil (Bancoob).
O sistema de cooperativismo de crédito no Brasil é estruturado em três níveis, sendo o primeiro nível formado por 1.020 cooperativas de crédito singulares, o segundo nível por 35 cooperativas centrais e o terceiro por quatro Confederações e 2 bancos cooperativos, conforme pode ser visualizado na figura 1.

Figura 1- Organização do Sistema Nacional de Crédito Cooperativo.

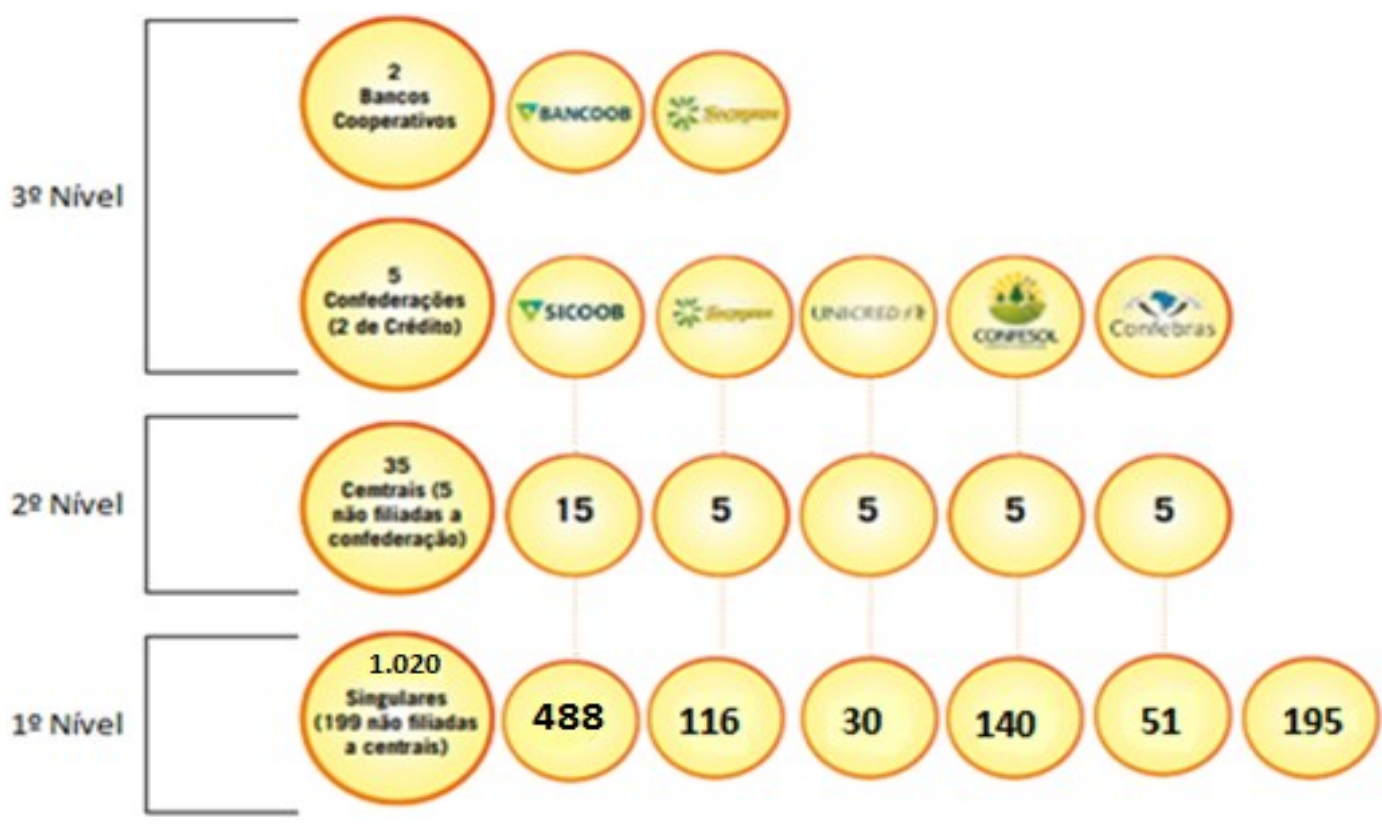

Fonte: Adaptada de Serviço Nacional de Aprendizagem do Cooperativismo (2016, p. 60).

Essa estrutura verticalizada de trabalho sistêmico possibilita ganho de escala e redução de custos como desenvolvimento e manutenção dos terminais de autoatendimento (ATM). Permite ainda ao cooperado acesso, mesmo fora de sua cidade. Viabiliza o desenvolvimento de estruturas tecnológicas próprias e mais adequadas às necessidades dos cooperados, como plataformas mobile banking e soluções de pagamento, por via eletrônica. Possibilita oferecer ampla variedade de produtos, serviços e soluções para seus cooperados, similar à oferecida por outras instituições financeiras, evitando-se assim que o cooperado dependa dos bancos tradicionais, fidelizando-o à cooperativa.

\subsubsection{Cooperativas Singulares}

No primeiro nível, de acordo com o Serviço Nacional de Aprendizagem do Cooperativismo (2016, p. 59), encontram-se as "As cooperativas singulares, que atendem diretamente os associados, podem constituir cooperativas centrais, que por sua vez podem se 
organizar em confederações e também constituir bancos cooperativos". Algumas cooperativas singulares optam por atuar de forma independente, sem filiação a sistemas. A maioria, contudo, se organiza de forma sistêmica, compartilhando entre si sistemas e serviços, visando ganhos de escala e eficiência. Esse tipo de cooperativa, para sua constituição, a legislação exige no mínimo 20 associados pessoas físicas e/ou jurídicas. Tem como característica principal a prestação serviços diretamente aos associados.

\subsubsection{Cooperativas Centrais ou Federações de Cooperativas}

No segundo nível, o Serviço Nacional de Aprendizagem do Cooperativismo (2016), encontram as Cooperativas Centrais, com o objetivo de organizar, em comum e em maior escala, os serviços econômicos e assistenciais de interesse das filiadas, integrando e orientando suas atividades, bem como facilitando a utilização recíproca dos serviços. São constituídas por, no mínimo, três cooperativas singulares. Somente as cooperativas centrais de crédito são consideradas instituições financeiras pelo SFN (CARDOSO, 2014).

\subsubsection{Confederações e Bancos Cooperativos}

As confederações e os bancos cooperativos compõem o terceiro nível do SNCC. A primeira é formada por, no mínimo, três centrais ou federações da mesma ou de diferentes modalidades, responsável pela centralização dos recursos captados, a padronização dos serviços oferecidos, fornecendo maior escala em sistemas operacionais, tecnológicos e de serviços internos. Para que uma confederação de cooperativas de crédito seja considerada instituição financeira, é necessária à aprovação pelo BACEN. Atualmente, somente a Confederação UNICRED tem esse status.

Os Bancos Cooperativos podem ser comerciais ou múltiplos, constituídos obrigatoriamente, com carteira comercial, com, no mínimo, $51 \%$ das ações com direito a voto. Oferecem produtos e serviços financeiros às cooperativas, ampliando e criando novas possibilidades de negócios e gestão centralizada dos recursos financeiros do sistema. No Brasil, atualmente, existem dois bancos cooperativos, o primeiro, o Banco Bancoob, um banco comercial privado com enfoque no atendimento às cooperativas de crédito, cujo controle acionário pertence às entidades filiadas ao SICOOB; o segundo, o Banco SICREDI, foi o primeiro banco cooperativo privado do Brasil com enfoque no atendimento às cooperativas de crédito do SICREDI (FGCOOP, 2017).

As quatro confederações que formam o terceiro nível, no Brasil, são o SICOOB, Sistema de crédito Cooperativo (SICREDI), Confederação Nacional das Cooperativas Centrais (UNICREDI), e Associação Nacional de Cooperativismo de Crédito e Economia Solidária (ANCOSOL), considerados grandes sistemas cooperativos de créditos. Pertencer a 
algum sistema de cooperativa de crédito traz mais segurança em termos de estrutura e solidez dos recursos movimentados pelos cooperados, uma vez que todas as movimentações são acompanhadas, monitoradas, auditadas, além de contar com apoio político, econômico, social e financeiro por parte das confederações (FRANCISCO, 2014).
Nesse contexto, pertencer a um sistema cooperativo de créditos, permite o acesso à tecnologia, aos produtos e aos serviços mais eficientes, procedimentos de controles internos e divulgação da marca. O gráfico 1 apresenta a evolução das cooperativas singulares pertencente a cada confederação de 2012 a $2017^{1}$.

Gráfico 1 - Evolução do sistema de cooperativas de crédito de terceiro nível.

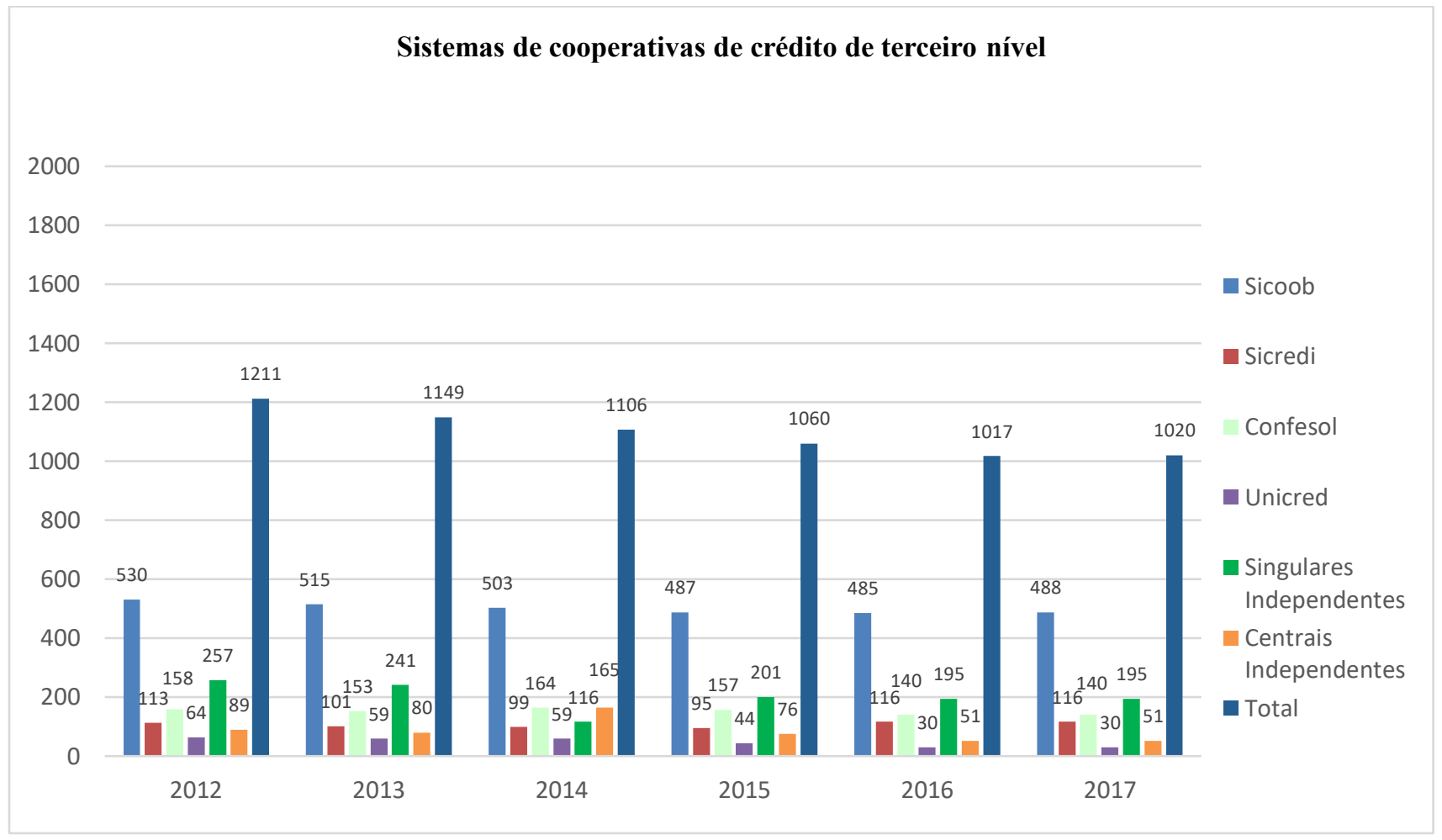

Fonte: Elaborado pelos autores (2017).

De acordo com BACEN (2016), o segmento cooperativista de crédito passa por um processo de consolidação iniciado há alguns anos, na busca por ganho de escala e maior eficiência operacional. Assim, algumas cooperativas de crédito tiveram o cancelamento das autorizações para funcionamento, além da redução de autorizações. Assim, o número de cooperativas de crédito singulares em atividade vem diminuindo nos últimos anos. O gráfico 2 apresenta a composição dos sistemas cooperativos de créditos no ano de 2017.

\footnotetext{
${ }^{1}$ BACEN (2017 a) consulta efetuada em 15 de outubro
} de 2017. 
Gráfico 2 - Quantidade e percentual das cooperativas de crédito por sistema de terceiro nível.

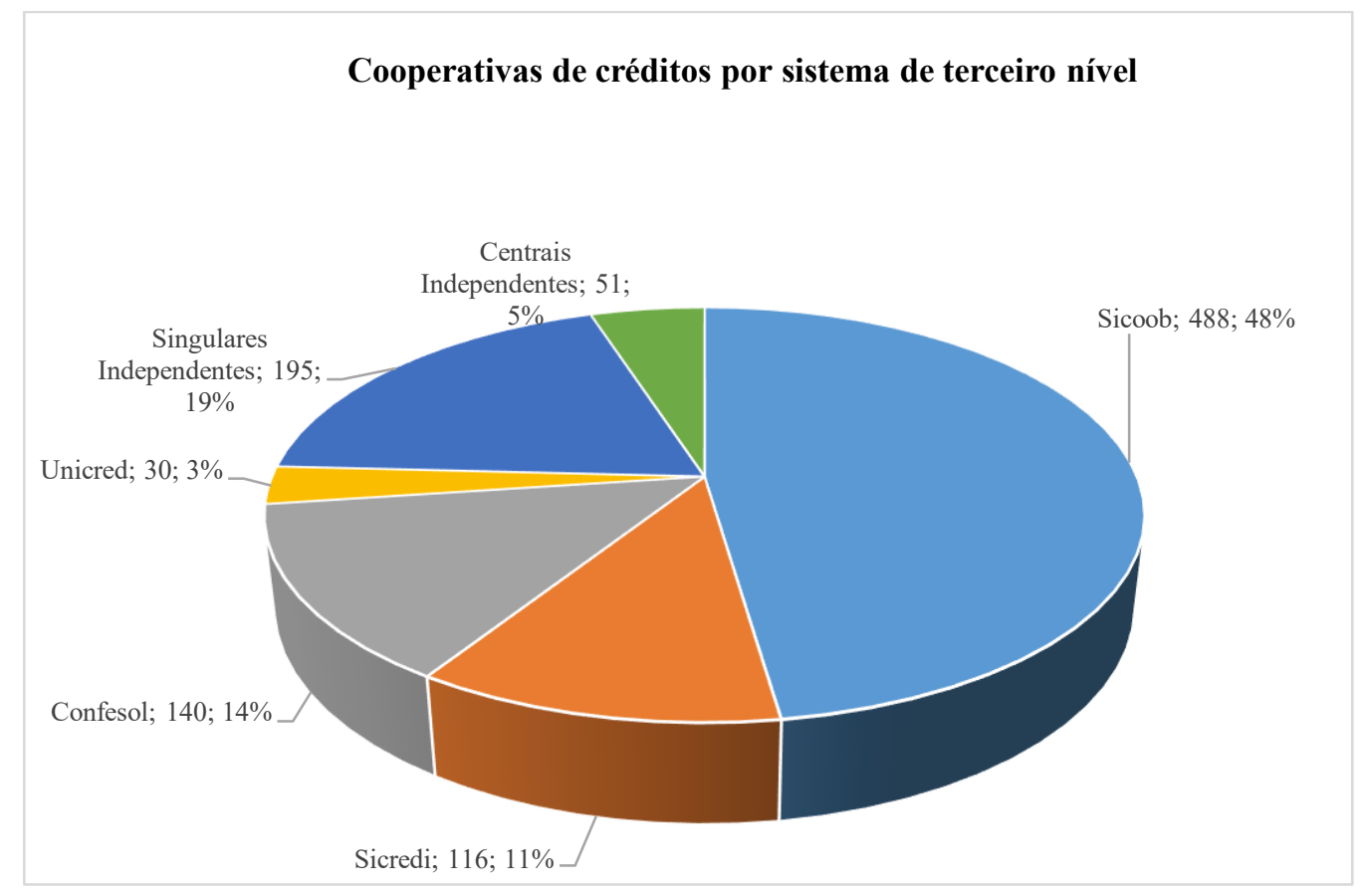

Fonte: Elaborado pelos autores (2017).

O sistema SICOOB predomina com 488 cooperativas singulares, o que corresponde a $48 \%$ do total das cooperativas do primeiro nível. Em segundo lugar estão as cooperativas singulares independentes, no total de 195, representando $19 \%$ do total. Em terceiro, o sistema CONFESOL, com 140 cooperativas, representando $14 \%$ do total. Em quarto e quinto está o sistema SICRED e UNICRED, com 140 e 116 , representando $14 \%$ e $11 \%$ respectivamente das cooperativas do sistema de primeiro nível.

O Sistema SICOOB opera com o Banco Cooperativo BANCOOB S/A, sendo este um banco múltiplo, privado e especializado no atendimento a cooperativas de crédito, cujo controle acionário pertence a entidades filiadas ao SICOOB. Constituído em 1996, com a finalidade de estimular o desenvolvimento do cooperativismo de crédito no País (BANCOOB, 2017).

Já o Sistema SICREDI opera com o Banco Cooperativo BANSICREDI S/A, foi o primeiro banco cooperativo privado que teve acesso aos produtos e serviços bancários. Criado em 1995, sua atuação é voltada ao atendimento das demandas do quadro social das cooperativas de crédito do sistema SICREDI e também daquelas com as quais mantém convênios específicos de prestação de serviços (SICREDI, 2017).

O Sistema UNICRED opera com Banco Cooperativo BANSICREDI S/Ae Banco do Brasil S/A. Criado em 1989, formado por um conjunto de instituições financeiras cooperativas, com forma e natureza jurídica próprias, de natureza civil, sem fins lucrativos e não sujeitas à falência, normatizadas pela 
legislação cooperativista e do Sistema Financeiro Nacional (UNICRED, 2017).

O Sistema CONFESOL opera com o Banco Nacional do Desenvolvimento Econômico e Social e Banco do Brasil S/A. Com o primeiro, negocia recursos do microcrédito produtivo orientado, recursos concedidos para as necessidades financeiras de pessoas físicas e jurídicas aplicadas em atividades produtivas de pequeno porte como os microempreendedores, de acordo com a Lei n. ${ }^{\circ}$ 11.110, de 25 de abril de 2005 (CONFESOL, 2017). Com o segundo, atua na intermediação do Programa Nacional de Fortalecimento da Agricultura Familiar (PRONAF) (BIANCHINI, 2015) .

\subsection{Classificação das Cooperativas de Crédito no Brasil}

A Resolução n. ${ }^{o}$ 5764, de 16 de dezembro de 1971, no artigo 10, definiu que as cooperativas de crédito poderiam ser classificadas de acordo com o objeto ou natureza das atividades desenvolvidas por elas ou por seus associados. A Resolução n. ${ }^{0} 3.442$, de 28 de fevereiro de 2007, revogou a

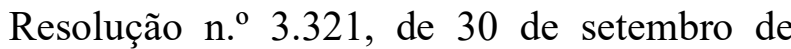
2005, destacou avanços como definição de critérios para admissão de cooperados e a possibilidade de transformação de cooperativas de crédito em livre admissão em áreas de ação com até dois milhões de habitantes, além da possibilidade de constituição de cooperativas de crédito mistas de empresários e outras categorias e da previsão de constituição de uma entidade de auditoria cooperativa.

O CMN, nos artigos 12 e 13 da Resolução n. ${ }^{\circ} 3.859$, de 27 de maio de 2010, que alterou e consolidou as normas relativas à constituição e ao funcionamento de cooperativas de crédito, estabeleceu condições de admissão de pessoas físicas e as classificou de acordo com sua constituição, conforme apresentado no quadro 2 .

Quadro 2 - Classificação das cooperativas de crédito no Brasil.

\begin{tabular}{|l|l|}
\hline \multicolumn{1}{|c|}{$\begin{array}{c}\text { Classificação das } \\
\text { cooperativas de créditos }\end{array}$} & \multicolumn{1}{c|}{ Constituídas por } \\
\hline Empregados ou servidores & $\begin{array}{l}\text { Profissionais privados ou servidores públicos de uma mesma instituição ou cujas } \\
\text { atividades sejam afins, complementares, correlatas ou pertencentes a um mesmo } \\
\text { conglomerado econômico. }\end{array}$ \\
\hline Profissionais liberais & $\begin{array}{l}\text { Trabalhadores dedicados a uma ou mais atividades com objetivos afins, } \\
\text { complementares ou correlatos como advogados, engenheiros, contadores entre } \\
\text { outros. }\end{array}$ \\
\hline Crédito rural & $\begin{array}{l}\text { Pessoas que desenvolvam atividades agrícolas, pecuárias ou extrativas, dediquem- } \\
\text { se a operações de captura ou transformação do pescado. }\end{array}$ \\
\hline $\begin{array}{l}\text { Pequenos empresários, } \\
\text { microempresários e } \\
\text { microempreendedores }\end{array}$ & $\begin{array}{l}\text { Profissionais pertencentes a essas categorias, com receita bruta anual estabelecida } \\
\text { pela Lei Geral das Micro e Pequenas Empresas. }\end{array}$ \\
\hline Empresários & $\begin{array}{l}\text { Empresários participantes de empresas vinculadas direta ou indiretamente a } \\
\text { sindicatos patronais ou a associações patronais, de qualquer nível. }\end{array}$ \\
\hline Livre admissão & $\begin{array}{l}\text { Pessoas físicas e a maioria das pessoas jurídicas, exceto as que exerçam concorrência } \\
\text { com a sociedade cooperativa ou sejam governamentais. }\end{array}$ \\
\hline
\end{tabular}

Fonte: Elaborado pelos autores (2017). 
A tabela 1 apresenta a quantidade e os classificação no Brasil, de acordo com o percentuais das cooperativas de crédito por BACEN (2017 b).

Tabela 1 - Classificação das cooperativas de crédito.

\begin{tabular}{|c|c|c|}
\hline Classificação das cooperativas de crédito & Quantidade & Porcentagem \\
\hline Livre Admissão & 345 & $33,82 \%$ \\
\hline Empregados ou Servidores & 338 & $33,14 \%$ \\
\hline Produtor Rural & 114 & $11,18 \%$ \\
\hline Atividade Profissional & 84 & $8,24 \%$ \\
\hline Critérios de Associação Mistos - Outros & 48 & $4,71 \%$ \\
\hline Sem Classificação & 37 & $3,63 \%$ \\
\hline Empresários & 27 & $2,65 \%$ \\
\hline Critérios de Associação Mistos - Empresários & 24 & $2,35 \%$ \\
\hline Natureza Associativa ou Cadeia de Negócios & 3 & $0,29 \%$ \\
\hline Total & 1.020 & $100,00 \%$ \\
\hline
\end{tabular}

Fonte: Elaborada pelos autores (2017).

No Brasil, predominam as cooperativas de livre admissão, com 345 unidades, seguida das cooperativas de empregados ou servidores, com 338, representando respectivamente $33,82 \%$ e $33,14 \%$ do total das cooperativas de crédito.

\subsection{Categorias das Cooperativas de Crédito no Brasil}

A Resolução n. ${ }^{\circ} 4.434$, de 05 de agosto de 2015, apresentou um aprimoramento na regulamentação legal, categorizou as cooperativas de crédito em três tipos: plenas, clássicas e de capital e empréstimo, conforme apresentado no quadro 3 .

Quadro 3 - Categorias das cooperativas de crédito no Brasil.

\begin{tabular}{|l|l|}
\hline \multicolumn{1}{|c|}{ Categorias } & \multicolumn{1}{c|}{ Descrição } \\
\hline $\begin{array}{l}\text { Cooperativa de } \\
\text { crédito plena }\end{array}$ & $\begin{array}{l}\text { Autorizadas a realizar todas as operações atinentes às cooperativas de crédito } \\
\text { e, em geral, incluirão as entidades mais sofisticadas e de maior porte. }\end{array}$ \\
\hline $\begin{array}{l}\text { Cooperativa de } \\
\text { crédito clássica }\end{array}$ & $\begin{array}{l}\text { Autorizadas a realizar somente as operações atualmente permitidas no regime } \\
\text { prudencial simplificado (Resolução Bacen n. }{ }^{\circ} 4.194, \text { de 01 de maro de 2013), } \\
\text { sendo-lhes vedado realizar operações sujeitas à variação cambial, ao preço } \\
\text { mercadorias ou ações, ou ainda em instrumentos financeiros derivativos, dentre } \\
\text { outros. }\end{array}$ \\
\hline $\begin{array}{l}\text { Cooperativa de } \\
\text { crédito de capital } \\
\text { e empréstimo }\end{array}$ & $\begin{array}{l}\text { Estão sujeitas às mesmas limitações das cooperativas de crédito clássicas e ainda } \\
\text { não estão autorizadas a captar recursos ou depósitos, tendo assim como principal } \\
\text { fonte de recursos para o desempenho de suas atividades o capital próprio } \\
\text { integralizado por seus associados. Em geral, as cooperativas de crédito de capital e } \\
\text { empréstimo incluirão as entidades com estrutura organizacional e financeira com } \\
\text { padrões simplificados. }\end{array}$ \\
\hline
\end{tabular}

Fonte: Elaborado pelos autores (2017). 
As cooperativas de crédito plenas podem praticar todas as operações financeiras; já as clássicas têm algumas restrições como a operação com moeda estrangeira, com variação cambial e com derivativos. A cooperativa de capital e empréstimo é proibida de captar recursos ou depósitos, sendo sua fonte de financiamento apenas o capital próprio integralizado pelos cooperados, conforme apresentado no quadro 3. A Resolução n. 4.434, de 5 de agosto de 2015, em seu artigo 17, descreve a relação de todas as operações e atividades permitidas que podem ser realizadas por estas instituições, ensejando a partir dela o enquadramento das cooperativas. A tabela 2 apresenta a quantidade e o percentual de cada categoria de cooperativas.

Tabela 2 - Categorias das cooperativas singulares.

\begin{tabular}{l|c|c}
\hline Categorias das cooperativas singulares & Quantidade & \% \\
\hline Clássica & 755 & $74,02 \%$ \\
Capital e Empréstimo & 191 & $18,73 \%$ \\
Plena & 37 & $3,63 \%$ \\
Sem Classificação & 37 & $3,63 \%$ \\
\hline Total & $\mathbf{1 . 0 2 0}$ & $\mathbf{1 0 0 , 0 0 \%}$ \\
\hline
\end{tabular}

Fonte: Elaborada pelos autores (2017).

No Brasil, de acordo com BACEN (2017 b), predominam as cooperativas clássicas, com 775 unidades, seguidas das de Capital Empréstimo, com 191 unidades, representando respectivamente $74,02 \%$ e $18,73 \%$ do total das cooperativas de crédito. As cooperativas clássicas, além da intermediação financeira, ofertam produtos e serviços, realizam operações que antes constavam apenas no portfólio dos bancos, tais como seguros, cartões, previdência complementar, consórcios e cobrança bancária, justificando sua preponderância em relação às outras categorias (MEINEN; PORT, 2012).

\subsubsection{Expansão das Cooperativas de Crédito no Brasil}

O percentual de cooperados no Brasil aumentou, significativamente, no período de 2006 a 2016, registrou crescimento de 1,46\% para $4,38 \%$, o que corresponde a um aumento de $193,96 \%$ no percentual de cooperados em relação ao total da população. Nesse período, a população que passou a utilizar os serviços das cooperativas de crédito, aumentou de 2,77 para 8,86 milhões de pessoas.

As cooperativas de crédito no Brasil cresceram, principalmente após a liberação do BACEN para a possibilidade de livre admissão de associados, o que fomentou a formação de um conjunto de cooperados com interesse distintos (FONTES FILHO, COELHO E VENTURA, 2009). Além disso, as taxas e 
juros reduzidos aliando ampliação do número de cooperativas e agências contribuíram para essa expansão.
O gráfico 3 apresenta a evolução do número e do percentual de cooperados em relação ao total da população.

Gráfico 3 - Evolução do número e percentual de cooperados de créditos.

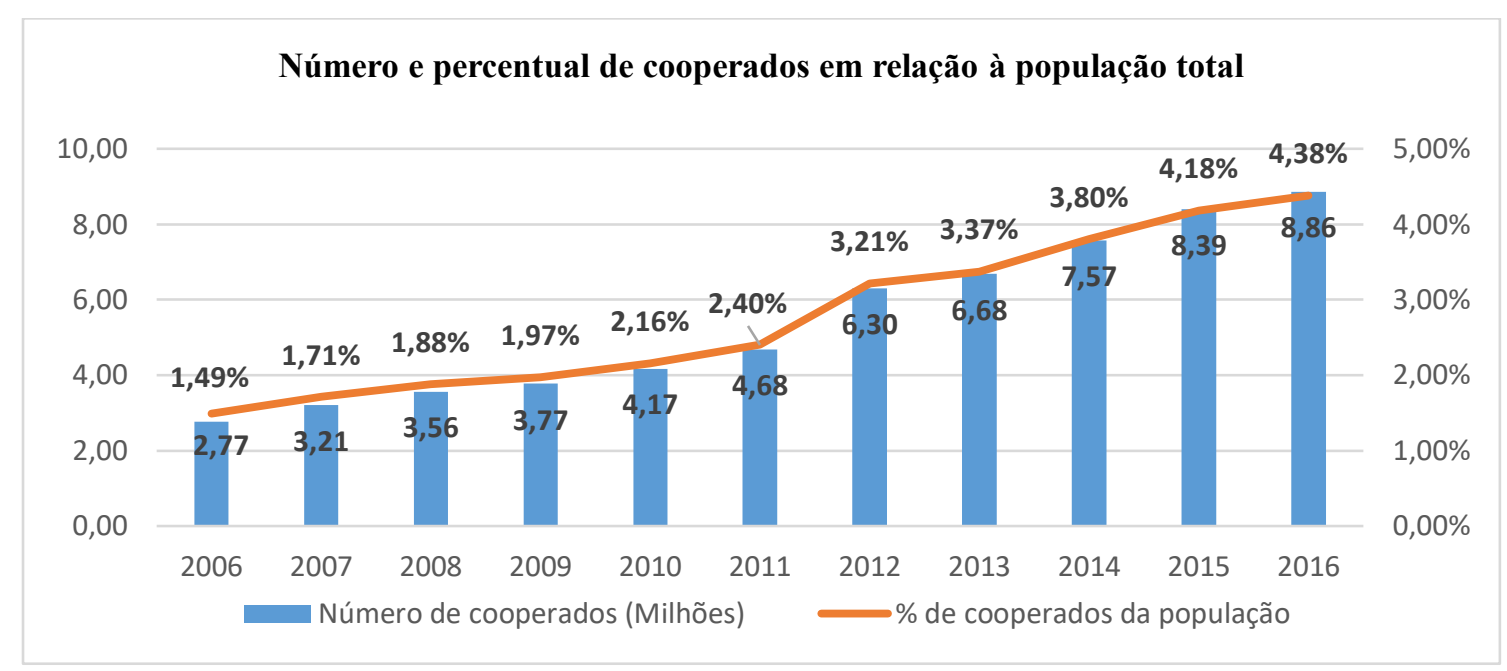

Fonte: Adaptado FGCoop (2016, p.4).

Em 2016, nas regiões Sul, Sudeste, Centro Oeste, Norte e Nordeste, respectivamente, $91 \%, 54 \%, 52 \%, 22 \%$ e $9 \%$ das cidades destas regiões eram atendidas pelas cooperativas de crédito. Na região Sul, 13,9\% da população já era associada ao Sistema Nacional de Crédito Cooperativo. Com relação ao país, 4,38\% da população já possuía conta vinculada a uma cooperativa, aumento de 36,45\% em relação a 2012 (BACEN, 2016). A tabela 3 apresenta as maiores instituições financeiras com relação às unidades de atendimento.

Tabela 3 - Maiores instituições financeiras em unidades de atendimento e agências bancárias em 2016.

\begin{tabular}{ccc}
\hline Ordem & Instituição & $\begin{array}{c}\text { Quantidade de unidade } \\
\text { atendimento }\end{array}$ \\
\hline 1 & Cooperativas de Crédito & 5.633 \\
2 & Banco do Brasil & 5.440 \\
3 & Bradesco & 5.309 \\
4 & Itaú & 3.464 \\
5 & Caixa & 3.412 \\
\hline
\end{tabular}

Fonte: Adaptado FGCoop (2016, p.4).

As cooperativas de crédito ocupam o primeiro lugar em unidades de atendimento e agências bancárias, entre todas as instituições financeiras, com 5.633 unidades, seguida por
Banco do Brasil com 5.440 unidades, Banco Bradesco 5.309 unidades, Banco Itaú 3.464 unidades e Caixa Econômica Federal com 3.412 unidades. 
2.5 Cooperativas de Crédito por Estado e Região do Brasil

A maioria das cooperativas de crédito, em unidades, está localizada nas regiões Sudeste e Sul (BACEN, 2017 b), consideradas as regiões mais desenvolvidas do Brasil. O quadro 4 apresenta a quantidade e o percentual das cooperativas de crédito por estado e região.

Quadro 4 - Quantidade e percentual de cooperativa de crédito por Estado e Região.

\begin{tabular}{|c|c|c|c|c|c|}
\hline REGIÃO & ESTADO & TOTAL ESTADO & $\%$ ESTADO & $\begin{array}{c}\text { TOTAL } \\
\text { REGIÃO }\end{array}$ & \% REGIÃO \\
\hline \multirow{4}{*}{ 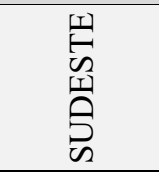 } & RJ & 51 & $5,00 \%$ & \multirow{4}{*}{494} & \multirow{4}{*}{$48,43 \%$} \\
\hline & SP & 223 & $21,86 \%$ & & \\
\hline & MG & 189 & $18,53 \%$ & & \\
\hline & ES & 31 & $3,04 \%$ & & \\
\hline \multirow{3}{*}{ S } & PR & 103 & $10,10 \%$ & \multirow{3}{*}{315} & \multirow{3}{*}{$30,88 \%$} \\
\hline & RS & 107 & $10,49 \%$ & & \\
\hline & $\mathrm{SC}$ & 105 & $10,29 \%$ & & \\
\hline \multirow{3}{*}{ 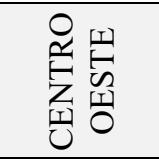 } & MT & 20 & $1,96 \%$ & \multirow{3}{*}{70} & \multirow{3}{*}{$6,86 \%$} \\
\hline & MS & 11 & $1,08 \%$ & & \\
\hline & GO & 39 & $3,82 \%$ & & \\
\hline \multirow{9}{*}{ 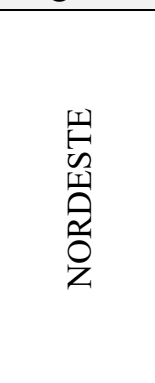 } & SE & 2 & $0,20 \%$ & \multirow{9}{*}{82} & \multirow{9}{*}{$8,04 \%$} \\
\hline & $\mathrm{RN}$ & 4 & $0,39 \%$ & & \\
\hline & PI & 2 & $0,20 \%$ & & \\
\hline & $\mathrm{PE}$ & 7 & $0,69 \%$ & & \\
\hline & PB & 15 & $1,47 \%$ & & \\
\hline & MA & 7 & $0,69 \%$ & & \\
\hline & $\mathrm{CE}$ & 5 & $0,49 \%$ & & \\
\hline & BA & 32 & $3,14 \%$ & & \\
\hline & $\mathrm{AL}$ & 8 & $0,78 \%$ & & \\
\hline \multirow{7}{*}{$\begin{array}{l}\text { Ir } \\
\text { 崩 } \\
\text { Z }\end{array}$} & TO & 1 & $0,10 \%$ & \multirow{7}{*}{44} & \multirow{7}{*}{$4,31 \%$} \\
\hline & RR & 1 & $0,10 \%$ & & \\
\hline & RO & 19 & $1,86 \%$ & & \\
\hline & PA & 12 & $1,18 \%$ & & \\
\hline & $\mathrm{AP}$ & 1 & $0,10 \%$ & & \\
\hline & AM & 6 & $0,59 \%$ & & \\
\hline & $\mathrm{AC}$ & 4 & $0,39 \%$ & & \\
\hline 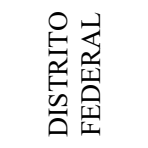 & $\mathrm{DF}$ & 15 & $1,47 \%$ & 15 & $1,47 \%$ \\
\hline \multicolumn{2}{|c|}{ TOTAL } & 1.020 & $100,00 \%$ & 1.020 & $100,00 \%$ \\
\hline
\end{tabular}

Fonte: Elaborado pelos autores (2017).

O cooperativismo de crédito concentrase nas regiões Sudeste, com 494 cooperativas, representando $48,43 \%$ e, no Sul, com 315 , representando $30,88 \%$, totalizando as duas regiões concentram $79,31 \%$ das cooperativas de crédito do país. A Participação das cooperativas de crédito no SFN por região e os estados com maior participação nos depósitos no Sistema Financeiro Estadual (SFE) são apresentados no gráfico 4. 
Gráfico 4 - Evolução do número e percentual de cooperados de créditos.

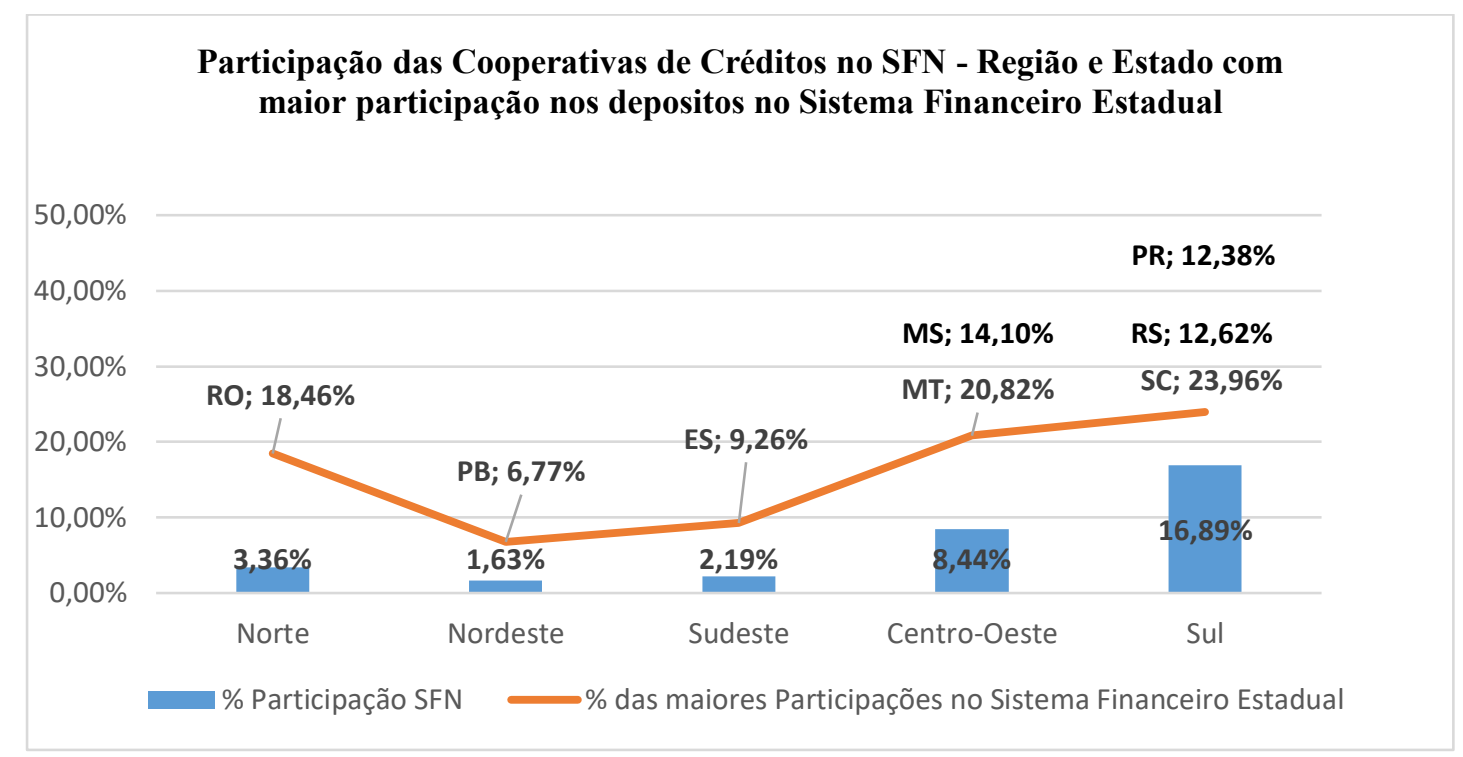

Fonte: Adaptado FGCoop (2016, p.6).

As regiões com maior participação das cooperativas de crédito nos depósitos do SFE são o Sul e Centro-Oeste com 16,89\% e 8,44\%, respectivamente. Na região Sul, as cooperativas de crédito dos estados de Rio Grande do Sul e Santa Catarina com representam 12,62\% e 23,96\%, respectivamente, dos depósitos no SFN. Na região Centro-Oeste, os estados do Mato Grosso do Sul e Mato Grosso representam $14,10 \%$ e $20,82 \%$ dos depósitos do SFE, respectivamente.

Em 2016, nas regiões Sul, Sudeste, Centro Oeste, Norte e Nordeste, 91\%, 54\%, $52 \%, 22 \%$ e $9 \%$, respectivamente, das cidades eram atendidas pelas cooperativas de crédito. $\mathrm{Na}$ região Sul, 13,9\% da população já era associada ao SNCC (BACEN, 2016).

\section{Participação das Cooperativas de Crédito no Sistema Financeiro Nacional}

Apesar do crescimento nos últimos anos, a participação das cooperativas no sistema financeiro, no Brasil, ainda é muito pequena quando comparada à União Europeia que tem participação de $20 \%$ das cooperativas de crédito no mercado de depósitos do SFN. Nos países como Áustria, França, Finlândia, Itália e Holanda, esta participação de mercado alcança patamares que variam de 25 a 50\%. Pessoas de baixa e média renda representam entre $20 \%$ e $50 \%$ dos cooperados e se encontram majoritariamente em áreas urbanas (SERVIÇO NACIONAL DE APRENDIZAGEM DO COOPERATIVISMO, 2016). A tabela 4 apresenta o volume das operações de créditos e a participação das cooperativas no SFN no Brasil. 
Tabela 4 - Participação das cooperativas de crédito no SFN em 2016.

\begin{tabular}{|c|c|c|c|}
\hline \multicolumn{2}{|r|}{ VOLUME DAS OPERAÇÕES DE CRÉDITO } & \multirow{2}{*}{\multicolumn{2}{|c|}{$\begin{array}{c}\text { Em RS mil } \\
\text { VOLUME }\end{array}$}} \\
\hline \multicolumn{2}{|r|}{ SEGMENTO } & & \\
\hline 1 & $\begin{array}{c}\text { Banco Comercial (+) Banco Múltiplo com carteira comercial (+) Caixa } \\
\text { Econômica Federal }\end{array}$ & $\mathbf{R S}$ & 2.632.775.219 \\
\hline 2 & Banco Múltiplo S/ carteira Comercial (+) Banco de Investimento & $\mathbf{R S}$ & 68.012.232 \\
\hline 3 & Banco de desenvolvimento & $\mathbf{R} \mathbf{S}$ & 363.166 .794 \\
\hline 4 & Inst. Não bancária de crédito & RS & 24.273.430 \\
\hline 5 & SNCC & $\mathbf{R} \$$ & 86.108.044 \\
\hline 5.1 & Banco Cooperativo (sem os repasses interfinanceiros) & $\mathrm{R} \$$ & 2.699 .513 \\
\hline 5.2 & Confederação & & - \\
\hline 5.3 & Central & $\mathrm{R} \$$ & 1.064 .557 \\
\hline 5.4 & Cooperativa Singular & $\mathrm{R} \$$ & 82.343 .974 \\
\hline \multicolumn{2}{|r|}{ Total SFN (Sem as Instituições Não Bancarias de Mercado de capitais) } & RS & 3.174.335.719 \\
\hline \multicolumn{2}{|r|}{ SNCC/SFN } & \multicolumn{2}{|r|}{$2,71 \%$} \\
\hline & Total SNCC Negociável $(5.1+5.4)$ & $\mathrm{R} \$$ & 85.043 .487 \\
\hline \multicolumn{2}{|c|}{ Participação SNCC negocial no consolidado bancário comercial $(5.1+5.4) /(1+5.1+5.4)$} & \multicolumn{2}{|r|}{$3,13 \%$} \\
\hline \multicolumn{2}{|r|}{ Participação SNCC negocial no consolidado bancário comercial mais as financeiras } & \multicolumn{2}{|r|}{$3,10 \%$} \\
\hline
\end{tabular}

Fonte: Adaptada FGCoop (2016, p.23).

O crédito do SFN, em 2016, totalizou 3,17 trilhões de reais, dos quais $2,71 \%$ corresponderam ao sistema de crédito cooperativo. A participação do SNCC negocial no consolidado bancário comercial representou $3,13 \%$, já a participação do SNCC negocial no consolidado bancário comercial mais a financeira representou $3,10 \%$, das operações financeiras em 2016 Quanto aos depósitos no SFN, destacam-se as regiões centro-oeste e sul, com $8,44 \%$ e $16,89 \%$, respectivamente, dos depósitos efetuados nas cooperativas de crédito.

\section{CONSIDERAÇÕES FINAIS}

O crescimento acelerado das cooperativas de crédito, nas últimas décadas, foi ocasionado principalmente pela autorização do Banco Central para prestar serviços bancários para o público sem exceções, com vínculo apenas regional. Além disso, as cooperativas de crédito se destacam por menores taxas sobre os empréstimos e custo das operações financeiras, além disso oferecem as maiores taxas de remuneração sobre os depósitos aplicados na cooperativa, comparado ao sistema bancário e financeiro.

$\mathrm{O}$ artigo teve como objetivo apresentar a estrutura do SNCC e sua participação no SFN no Brasil. O SNCC é estruturado em um sistema de três níveis, sendo o primeiro nível formado por 1.020 cooperativas de crédito singulares, o segundo nível por 35 cooperativas centrais e o terceiro nível por quatro Confederações e 2 bancos cooperativos. O sistema SICOOB predomina com 488 cooperativas singulares, o que corresponde a $48 \%$ do total das cooperativas do primeiro nível. 
Em relação às cooperativas de crédito, quanto à classificação, predominam as cooperativas de livre admissão, com 345 unidades, seguidas das cooperativas de empregados ou servidores, com 338, representando $33,82 \%$ e $33,14 \%$, respectivamente, do total das cooperativas de crédito. Quanto à categoria, predominam as cooperativas clássicas, com 775 unidades, seguidas das de Capital Empréstimo, com 191 unidades, representando, respectivamente, $74,02 \%$ e $18,73 \%$ do total das cooperativas de crédito.

O percentual de cooperados no Brasil aumentou, significativamente, no período de 2006 a 2016, foi registrado um crescimento de $1,46 \%$ para $4,38 \%$, respectivamente, o que corresponde a um aumento de 193,96\% no percentual de cooperados em relação ao total da população. Nesse período, a população que passou a utilizar os serviços das cooperativas de crédito foi de 2,77 para 8,86 milhões de pessoas. Esse aumento contribuiu para que as cooperativas de crédito ocupassem o primeiro lugar, com 5.633 unidades de atendimento e agências bancárias, entre todas as instituições financeiras. As cooperativas de crédito concentram-se nas regiões Sudeste, com 494 cooperativas, representando $48,43 \%$, e no Sul, com 315 , representando $30,88 \%$. Juntas as duas regiões totalizam $79,31 \%$ das cooperativas de crédito do país.
O SNCC representou apenas $2,71 \%$ do SFN, este último totalizou 3,17 trilhões de reais. O Total do SNCC negociável representou $3,13 \%$ do consolidado bancário comercial e $3,10 \%$ do consolidado comercial mais as financeiras em 2016. Já quanto aos depósitos no SFE destacam-se as regiões centro-oeste e sul, com $8,44 \%$ e $16,89 \%$ respectivamente dos depósitos efetuados nas cooperativas de crédito.

Apesar do crescimento nos últimos anos, a participação das cooperativas no sistema financeiro, no Brasil, ainda é muito pequena quando comparada com países como Áustria, França, Finlândia, Itália e Holanda. Essa participação de mercado alcança patamares que variam de 25 a 50\%. Por sua vez, pessoas de baixa e média renda representam entre $20 \%$ e $50 \%$ dos cooperados.A principal contribuição do estudo foi apresentar que a participação do SNCC no SFN ainda é incipiente, comparado a países desenvolvidos, necessitando de incentivos e investimentos para a expansão.

Finalmente foi possível inferir que, embora pequena quando comparada a outros países, a participação das cooperativas de crédito no SFN tem registrado crescimento constante. A expansão das cooperativas de crédito contribui para o desenvolvimento das regiões menos favorecidas pelos bancos comerciais, como as pequenas cidades, possibilitando assim a inclusão financeira da 
baixa renda e ampliação do microcrédito, além de fortalecer as pequenas empresas, responsáveis pela geração de emprego, mobilidade social, aumento da competitividade e efíciência econômica.

\section{REFERÊNCIAS}

ASSAF NETO, A. Mercado financeiro. 10. ed. São Paulo: Atlas, 2011.

BACEN. Panorama do sistema nacional de crédito cooperativo, 2016. Disponivel em: $<\mathrm{http}: / /$ www.bcb.gov.br/pre/microFinancas/co opcar/pdf/panorama_de_cooperativas.pdf $>$. Acesso em: 16 de outubro de 2017.

Banco Central do Brasil, 2017 a.

Disponivel em:

$<$ https://www.bcb.gov.br/Pre/bc_atende/port/c oop.asp> . Acesso em: 20 outubro 2017.

\section{Relação de Instituições em}

Funcionamento no País, 2017 b. Disponivel em:

$<$ https://www.bcb.gov.br/fis/info/instituicoes.a sp>. Acesso em: 28 outubro 2017.

\section{BANCOOB. Banco Cooperativo do Brasil}

S.A, 2017. Disponivel em: $<$ https://www.bancoob.com.br/conheca-obancoob>. Acesso em: 28 Outubro 2017.

BIANCHINI, V. Vinte anos do PRONAF, 1995 - 2015: avanços e desafios. Brasilia: SAF/MDA, 2015.

BRASIL. Decreto $N^{\circ}$ 979, de 6 de janeiro de 1903, 1903. Disponivel em:

$<$ http://www.planalto.gov.br/ccivil_03/decreto /Antigos/D0979.htm>. Acesso em: 18 outubro 2017.

\section{Decreto $\mathrm{N}^{\circ} \mathbf{1 . 6 3 7}$, de 5 de janeiro de}

1907, 1907. Disponivel em:

$<$ http://www2.camara.leg.br/legin/fed/decret/1 900-1909/decreto-1637-5-janeiro-1907- 582195-norma-pl.html>. Acesso em: 25 setembro 2017.

Decreto $\mathrm{N}^{0}$ 6.532, de 29 de junho de 1907, 1907. Disponivel em:

$<$ http://www.planalto.gov.br/ccivil_03/_Ato20 07-2010/2008/Decreto/D6532.htm $>$. Acesso em: 13 outubro 2017.

. Lei $\mathbf{N}^{\circ}$ 4.984, de 31 de dezembro de 1925, 1925. Disponivel em:

$<$ http://www2.camara.leg.br/legin/fed/lei/1920 -1929/lei-4984-31-dezembro-1925-563475republicacao-87967-pl.html>. Acesso em: 2017 setembro 25.

Decreto $\mathrm{N}^{0} \mathbf{2 2 . 2 3 9}$ de 19 de

dezembro de 1932, 1932. Disponivel em: $<$ http://www.planalto.gov.br/ccivil_03/decreto /1930-1949/D22239.htm>. Acesso em: 01 outubro 2017.

Decreto $\mathrm{N}^{\circ} \mathbf{2 4 . 6 4 7}$, de 10 de julho de 1934, 1934. Disponivel em: $<$ http://www.planalto.gov.br/ccivil_03/decreto /1930-1949/D24647.htm>. Acesso em: 2017 setembro 13.

Decreto-Lei $\mathrm{N}^{\circ} 581$, de $1^{\circ}$ de aosto de 1938, 1938. Disponivel em:

$<$ http://www.planalto.gov.br/ccivil_03/decreto -lei/1937-1946/Del581.htm>. Acesso em: 5 outubro 2017.

Decreto-Lei $N^{0}$ 5.893, de 19 de outubro de 1943, 1943. Disponivel em: $<$ http://www2.camara.leg.br/legin/fed/declei/1 940-1949/decreto-lei-5893-19-outubro-1943415859-publicacaooriginal-1-pe.html>. Acesso em: 21 setembro 2017.

Decreto-Lei ${ }^{\circ}$ 8.401, de 19 de dezembro de 1945, 1945. Disponivel em: $<$ http://www2.camara.leg.br/legin/fed/declei/1 940-1949/decreto-lei-8401-19-dezembro1945-416362-norma-pe.html>. Acesso em: 14 setembro 2017.

Lei $\mathrm{N}^{\circ} 1.079$, de 10 de abril de 1950 , 1950. Disponivel em: 
$<$ http://www.planalto.gov.br/ccivil_03/leis/L1 079.htm>. Acesso em: 1 outubro 2017.

. Lei $\mathrm{N}^{0} 1.412$, de 13 de agosto de 1951, 1951. Disponivel em: $<$ http://www2.camara.leg.br/legin/fed/lei/1950 -1959/lei-1412-13-agosto-1951-361901publicacaooriginal-1-pl.html>. Acesso em: 25 setembro 2017.

Decreto $\mathrm{N}^{0}$ 43.552, de 15 de abril de 1958, 1958. Disponivel em:

$<$ http://www2.camara.leg.br/legin/fed/decret/1 950-1959/decreto-43552-15-abril-1958382419-publicacaooriginal-1-pe.html $>$. Acesso em: 22 outubro 2017.

\section{Decreto do Conselho de Ministros} $\mathbf{N}^{\mathbf{0}} \mathbf{1 . 5 0 3}$, de 12 de novembro de 1962, 1962. Disponivel em:

$<$ http://www2.camara.leg.br/legin/fed/decmin/ 1960-1969/decretodoconselhodeministros1503-12-novembro-1962-352676publicacaooriginal-1-pe.html $>$. Acesso em: 21 setembro 2017.

Lei $\mathrm{N}^{0}$ 4.595, de 31 de dezembro de 1964, 1964. Disponivel em:

$<$ http://www.planalto.gov.br/ccivil_03/leis/L4 595.htm>. Acesso em: 30 setembro 2017.

Resolução BACEN No 11, de 20 de dezembro de 1965 (Revogado), 1965.

Disponivel em:

$<$ https://www.bcb.gov.br/pre/normativos/busc a/normativo.asp?tipo $=$ Resolu $\% \mathrm{C} 3 \% \mathrm{~A} 7 \% \mathrm{C} 3 \%$ A3o\&data $=1965 \&$ numero $=11>$. Acesso em: 12 setembro 2017.

Decreto-lei no 59, de 21 de

novembro de 1966 (Revogado), 1966.

Disponivel em:

$<$ http://www.planalto.gov.br/ccivil_03/decreto -lei/1965-1988/Del0059.htm>. Acesso em: 11 novembro 2017.

Resolução BACEN No 15, de 28 de janeiro de 1966 (Revogado), 1966.

Disponivel em:

$<$ https://www.bcb.gov.br/pre/normativos/busc a/normativo.asp?tipo $=$ Resolu $\% \mathrm{C} 3 \% \mathrm{~A} 7 \% \mathrm{C} 3 \%$ A3o\&data $=1966 \&$ numero $=15>$. Acesso em: 22 setembro 2017.

Resolução BACEN No 27, de 30 de junho de 1966 (Revogado), 1966. Disponivel em:

$<$ https://www.bcb.gov.br/pre/normativos/busc a/normativo.asp?tipo $=$ Resolu $\% \mathrm{C} 3 \% \mathrm{~A} 7 \% \mathrm{C} 3 \%$ A3o\&data $=1984 \&$ numero $=27>$. Acesso em: 25 agosto 2017.

Decreto $N^{0}$ 60.597, de 19 de abril de 1967, 1967. Disponivel em:

$<$ http://www2.camara.leg.br/legin/fed/decret/1 960-1969/decreto-60597-19-abril-1967-

401464-publicacaooriginal-1-pe.html>.

Acesso em: 26 setembro 2017.

Resolução BACEN No 99, de 19 de

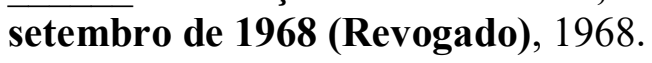

Disponivel em:

$<$ https://www.bcb.gov.br/pre/normativos/busc a/normativo.asp?tipo $=$ Resolu $\% \mathrm{C} 3 \% \mathrm{~A} 7 \% \mathrm{C} 3 \%$ A3o\&data $=1968 \&$ numero $=99>$. Acesso em: 20 setembro 2017.

Decreto-Lei $\mathrm{N}^{0} \mathbf{1 . 0 9 8}$, de 25 de março de 1970, 1970. Disponivel em: $<$ http://www2.camara.leg.br/legin/fed/declei/1 970-1979/decreto-lei-1098-25-marco-1970375405-norma-pe.html>. Acesso em: 15 setembro 2017.

Lei $\mathbf{N}^{0}$ 5.764, de 16 de dezembro de 1971, 1971. Disponivel em:

$<$ http://www.camara.gov.br/sileg/integras/258 460.pdf $>$. Acesso em: 1 outubro 2017.

\section{Constituição Federal do Brasil,}

1988. Disponivel em:

$<$ http://cooperativismodecredito.coop.br/legisl acao-e-gestao/constituicao-federal/ $>$. Acesso em: 23 OUTUBRO 2017.

Lei $\mathrm{N}^{0}$ 8.029, de 12 de abril de 1990, 1990. Disponivel em:

$<$ http://www.planalto.gov.br/ccivil_03/leis/L8 029cons.htm>. Acesso em: 10 setembro 2017. 
Resolução BACEN No 1.914, de 11

de março de 1992 (Revogado), 1992.

Disponivel em:

$<$ https://www.bcb.gov.br/pre/normativos/busc a/normativo.asp?tipo $=$ res\&ano $=1992 \&$ numero $=1914>$. Acesso em: 1 Outubro 2017.

Resolução BACEN No 2.099, de 17 de agosto de 1994, 1994. Disponivel em:

$<$ https://www.bcb.gov.br/pre/normativos/busc a/normativo.asp?tipo $=$ res\&ano $=1994 \&$ numero $=2099>$. Acesso em: 6 Outubro 2017.

Resolução BACEN No 2.193, de 31 de agosto de 1995 (Revogado), 1995.

Disponivel em:

$<$ https://www.bcb.gov.br/pre/normativos/busc a/downloadNormativo.asp?arquivo=/Lists/Nor mativos/Attachments/46112/Res_2193_v3_P. pdf $>$. Acesso em: 12 setembro 2017.

Resolução BACEN No 2.608, de 27

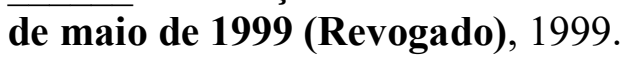

Disponivel em:

$<$ https://www.bcb.gov.br/pre/normativos/busc a/normativo.asp?tipo $=$ res\&ano $=1999 \&$ numero $=2608>$. Acesso em: 5 outubro 2017 .

Resolução BACEN No 2.771, de 30 de agosto de 2000 (Revogado), 2000.

Disponivel em:

$<$ https://www.bcb.gov.br/pre/normativos/busc a/normativo.asp?tipo $=$ Resolu $\% \mathrm{C} 3 \% \mathrm{~A} 7 \% \mathrm{C} 3 \%$ A3o\&data $=2000 \&$ numero $=2771>$. Acesso em: 27 setembro 2017.

Lei $\mathrm{N}^{\circ} \mathbf{1 0 . 4 0 6}$, de 10 de janeiro de 2002. O Código Cívil, 2002. Disponivel em: $<$ http://www.planalto.gov.br/ccivil_03/leis/20 02/L10406.htm>. Acesso em: 5 outubro 2017.

Resolução BACEN No 3.058, de 20 de dezembro de 2002 (Revogado), 2002. Disponivel em:

$<$ https://www.bcb.gov.br/pre/normativos/busc a/normativo.asp?tipo $=$ Resolu $\% \mathrm{C} 3 \% \mathrm{~A} 7 \% \mathrm{C} 3 \%$ $\mathrm{A} 3$ o\&data $=2002 \&$ numero $=3058>$. Acesso em: 14 outubro 2017.
. Resolução BACEN No 3.106, de 25

de junho de 2003 (Revogado), 2003.

Disponivel em:

$<$ https://www.bcb.gov.br/pre/normativos/busc a/normativo.asp?tipo $=$ Res\&ano $=2003 \&$ numer $\mathrm{o}=3106>$. Acesso em: 21 outubro 2017.

Resolução BACEN No 3.140, de 27 de novembro de 2003 (Revogado), 2003.

Disponivel em:

$<$ https://www.bcb.gov.br/pre/normativos/busc a/normativo.asp?tipo $=$ Resolu $\% \mathrm{C} 3 \% \mathrm{~A} 7 \% \mathrm{C} 3 \%$ $A 30 \& d a t a=2003 \&$ numero $=3140>$. Acesso em: 11 outubro 2017.

Resolução BACEN No 3.156, de 17 de dezembro de 2003 (Revogado), 2003.

Disponivel em:

$<$ https://www.bcb.gov.br/pre/normativos/busc a/normativo.asp?tipo $=$ Resolu $\% \mathrm{C} 3 \% \mathrm{~A} 7 \% \mathrm{C} 3 \%$ $\mathrm{A} 3 \mathrm{o} \&$ data $=2003 \&$ numero $=3156>$. Acesso em: 9 outubro 2017.

Resolução BACEN No 3.188, de 29 de março de 2004, 2004. Disponivel em: $<$ https://www.bcb.gov.br/pre/normativos/busc a/normativo.asp?tipo $=$ Resolu $\% \mathrm{C} 3 \% \mathrm{~A} 7 \% \mathrm{C} 3 \%$ A3o\&data $=2004 \&$ numero $=3188>$. Acesso em: 2 outubro 2017.

Resolução Conselho Federal de Contabilidade - CFC N ${ }^{\circ}$ 1.013, de 21 de janeiro de 2005, 2005. Disponivel em: $<$ http://www.portaldecontabilidade.com.br/nbc /res1013.htm > . Acesso em: 20 setembro 2017.

Resolução BACEN No 3.309, de 31 de agosto de 2005, 2005. Disponivel em: $<$ http://www.bcb.gov.br/pre/normativos/busca/ normativo.asp?tipo $=$ res $\&$ ano $=2005 \&$ numero $=$ 3309>. Acesso em: 25 setembro 2017.

. Resolução BACEN No 3.321, de 30 de setembro de 2005 (Revogado), 2005.

Disponivel em:

$<$ https://www.bcb.gov.br/pre/normativos/busc a/normativo.asp?tipo $=$ Resolu $\% \mathrm{C} 3 \% \mathrm{~A} 7 \% \mathrm{C} 3 \%$ A3o\&data $=2005 \&$ numero $=3321>$. Acesso em: 5 outubro 2017. 
Resolução BACEN No 3.442, de 28

de fevereiro de 2007 (Revogado), 2007.

Disponivel em:

$<$ http://www.bcb.gov.br/pre/normativos/busca/ normativo.asp?tipo $=$ Res\&ano $=2007 \&$ numero $=003442>$. Acesso em: 7 outubro 2017 .

Lei Complementar $\mathbf{N}^{0}$ 130, de 17 de abril de 2009, 2009. Disponivel em:

$<$ http://www.planalto.gov.br/ccivil_03/leis/LC P/Lcp130.htm>. Acesso em: 11 outubro 2017.

Resolução BACEN No 3.859, de 27

de maio de 2010 (Revogado), 2010.

Disponivel em:

$<$ https://www.bcb.gov.br/pre/normativos/busc a/normativo.asp?tipo $=$ res\&ano $=2010 \&$ numero $=3859>$. Acesso em: 13 outubro 2017 .

Resolução BACEN No 4072, de 26

de abril de 2012, 2012. Disponivel em:

$<$ https://www.legisweb.com.br/legislacao/?id= 240745>. Acesso em: 2 outubro 2017.

Resolução BACEN No 4.243, de 28

de junho de 2013 (Revogado), 2013.

Disponivel em:

$<$ https://www.bcb.gov.br/pre/normativos/busc a/normativo.asp?tipo $=$ res\&ano $=2013 \&$ numero $=4243>$. Acesso em: 6 outubro 2017 .

Resolução BACEN No 4.284, de 5 de novembro de 2013, 2013. Disponivel em: $<$ http://www.bcb.gov.br/pre/normativos/res/20 13/pdf/res 4284 v1 O.pdf $>$. Acesso em: 6 outubro 2017 .

Resolução BACEN No 4.194, de 1 de março de 2013, 2013. Disponivel em: $<$ https://www.bcb.gov.br/pre/normativos/busc a/downloadNormativo.asp?arquivo=/Lists/Nor mativos/Attachments/49005/Res_4194_v1_O. pdf $>$. Acesso em: 13 setembro 2017.

Resolução BACEN No 4.434, de 5 de agosto de 2015, 2015. Disponivel em: $<$ https://www.bcb.gov.br/pre/normativos/busc a/downloadNormativo.asp?arquivo=/Lists/Nor mativos/Attachments/48507/Res 4434 v1 O. pdf $>$. Acesso em: 9 outubro $201 \overline{7}$.
Resolução BACEN No 4.454, de 17 de dezembro de 2015, 2015. Disponivel em: $<$ https://www.bcb.gov.br/pre/normativos/busc a/downloadNormativo.asp?arquivo=/Lists/Nor mativos/Attachments/50124/Res_4454_v2_L. pdf $>$. Acesso em: 12 setembro 2017.

Resolução BACEN No 4.538, de 24 de novembro de 2016, 2016. Disponivel em: $<$ https://www.bcb.gov.br/pre/normativos/busc a/normativo.asp?numero $=4538 \&$ tipo $=$ Resolu $\% \mathrm{C} 3 \% \mathrm{~A} 7 \% \mathrm{C} 3 \% \mathrm{~A} 3 \mathrm{o} \&$ data $=24 / 11 / 2016>$.

Acesso em: 8 outubro 2017.

Resolução BACEN No 4.553, de 30 de janeiro de 2017, 2017. Disponivel em: $<$ https://www.bcb.gov.br/pre/normativos/busc a/downloadNormativo.asp?arquivo=/Lists/Nor mativos/Attachments/50335/Res_4553_v1_O. pdf $>$. Acesso em: 15 outubro $20 \overline{17}$.

BRESSAN, V. G. F. et al. Brazilian Credit Union Member Groups: Borrower-dominated. Brazillian Administration Review, p. 41-56, 2013.

CARDOSO, U. C. Cooperativa Financeira. Brasilia: Sebrae, 2014.

CONFESOL. Cooperativa de Crédito Rural Solidário, 2017. Disponivel em:

$<$ http://www.cresolconfederacao.com.br/>. Acesso em: 12 Outubro 2017.

FGCOOP, F. G. D. C. D. C. Relatório Anual do Sistema Nacional de Crédito Cooperativo - SNCC - 2016, 2016.

Disponivel em:

$<$ http://www.fgcoop.coop.br/documents/19/43 822/RELAT\%C3\%93RIO+ANUAL+2016.pdf /9c13aca0-7141-440a-9147-94097e59cf76>.

Acesso em: 15 de outubro de 2017.

Fundo Garantidor do

Cooperativismo de Crédito, 2017.

Disponivel em:

$<$ http://www.fgcoop.coop.br/banco-

cooperativo $>$. Acesso em: 25 outubro 2017. 
FONTES FILHO, J. R.; COELHO, F. C.; VENTURA, E. C. F. Governança em Cooperativas de Créditos: Singularidade no Caso Brasileiro. In: VENTURA, E. C. F.; FONTES FILHO, J. R.; SOARES, M. M. Governança Cooperativa: Diretrizes e mecanismos para fortalecimento da governança em cooperativas de créditos. Brasilia: BCB, 2009. p. 63-87.

FRANCISCO, J. R. D. S. Índice de Governança Corporativa: criação de valor e desempenho nas cooperativas de crédito. Tese (Doutorado) Universidade Federal de Minas Gerais. Belo Horizonte, p. 186. 2014.

MEINEN, E.; PORT, M. O cooperativismo de crédito ontem, hoje e amanhã. Brasilia: Confebrás, 2012.

PINHEIRO, M. A. H. Cooperativas de Créditos: história e evolução normativa no Brasil. 6. ed. Brasilia: BCB, 2008.

SANTOS, S. D. D. Práticas de Governança e Desempenho Financeiro em Cooperativas de Créditos. Dissertação (Mestrado) Universidade de São Paulo - USP. São Paulo, p. 212. 2016.

SERVIÇO NACIONAL DE APRENDIZAGEM DO COOPRATIVISMO. Cooperativismo de Crédito: boas práticas no Brasil e no Mundo. Brasília: Farol Estratégicas em Comunicação, 2016. 204 p.

SICREDI. Sistema de Crédito Cooperativo, 2017. Disponivel em:

$<$ https://www.sicredi.com.br/html/>. Acesso em: 26 outubro 2017.

UNICRED. Sistema Unicred, 2017.

Disponivel em:

$<$ https://www.unicred.com.br/>. Acesso em:

21 Outubro 2017. 